\title{
FONTES DE CRÉDITO (EMPRÉSTIMOS E FINANCIAMENTOS) DISPONÍVEIS PARA ORGANIZAÇÕES DE CATADORES DE MATERIAIS REUTILIZÁVEIS E RECICLÁVEIS
}

\author{
Patrícia Lopes Freire Pupin \\ Universidade Estadual Paulista "Júlio de Mesquita Filho", Instituto de Geociências e Ciências Exatas, Pós- \\ Graduação em Geografia, Rio Claro, SP, Brasil \\ patricialopesfreire@ hotmail.com
}

Lívia Martinez Brumatti Universidade de São Paulo, Faculdade de Economia, Administração e Contabilidade, Pós-Graduação em Controladoria e Contabilidade, Ribeirão Preto, SP, Brasil lmbrumatti@usp.br

Ana Claudia Giannini Borges Universidade Estadual Paulista “Júlio de Mesquita Filho”, Instituto de Geociências e Ciências Exatas, Rio Claro, SP, Brasil ana.giannini@unesp.br

\begin{abstract}
RESUMO
A demanda por recursos financeiros é uma necessidade recorrente nas Organizações de Catadores de Materiais Reutilizáveis e Recicláveis (OCMRR). No entanto, existe uma carência na oferta de crédito (seja de empréstimos ou de financiamentos) no mercado tradicional e isto influencia consideravelmente a organização financeira das OCMRR. Visto isso, objetivou-se identificar e analisar as fontes de crédito (empréstimos e financiamentos) disponíveis para essas OCMRR do estado de São Paulo, apontando dificuldades e desafios. Para tanto, foi realizado um levantamento destas informações junto a instituições financeiras tradicionais no estado de São Paulo, bem como em instituições públicas envolvidas na temática de Resíduos Sólidos. Foi possível identificar que a oferta desses recursos é deficitária no estado, pois os bancos tradicionais não apresentam linhas específicas para esses tipos de empreendimentos. Além disso, as OCMRR ficam dependentes da atuação conjunta com Prefeituras Municipais e/ou Instituições de Ensino para a elaboração de projetos e captação de recursos. Por fim, evidencia-se que há um hiato entre as condições requeridas pelas fontes de crédito e a condição apresentada pelas OCMRR, indicando situação de exclusão financeira dessas organizações.
\end{abstract}

Palavras-chaves: Recursos financeiros; Resíduos sólidos; OCMRR.

\section{SOURCES OF CREDIT (LOANS AND FINANCING) AVAILABLE TO REUSABLE AND RECYCLE MATERIAL PICKER ORGANIZATIONS}

\begin{abstract}
Demand for financial resources is a recurrent need in Reusable and Recyclable Material Picker Organizations (OCMRR in Portuguese acronym). However, there is a lack of credit supply (either loans or financing) in the traditional market, and this has a considerable influence on the financial organization of the OCMRR. To evidence this, the purpose of this paper is to identify and analyze the sources of credit (loans and financing) available for the OCMRR in the state of São Paulo, pointing out difficulties and challenges. To do so, we collected information from traditional financial institutions in the state of São Paulo, as well as in public institutions involved in the Solid Waste theme. It was possible to identify that the supply of financial resources is deficient in the state since the traditional banks do not present specific lines for these types of organization. Also, the OCMRR are dependent on joint action with Municipal City Halls or Universities for the preparation of projects for fundraising. Finally, it is evident that there is a gap between the conditions required by the sources of credit and the condition presented by the OCMRR, indicating the situation of financial exclusion of these organizations.
\end{abstract}

Keywords: Financial resources; Solid waste; OCMRR.

$\begin{array}{llllll}\text { Caminhos de Geografia } & \text { Uberlândia - MG } & \text { v. 20, n. } 70 & \text { Junho/2019 } & \text { p. 158-178 Página } 158\end{array}$




\title{
INTRODUÇÃO
}

Os catadores de materiais reutilizáveis e recicláveis são trabalhadores que realizam o trabalho de catação, separação e venda de resíduos sólidos da sociedade de consumo. Alguns destes, na busca de apoio e trabalho solidário, agrupam-se em associações ou cooperativas. Costa e Chaves (2012, p. 2) observam que "as diversas oscilações e mutações do capitalismo engendraram novas possibilidades de (re)pensar os sentidos do trabalho no limiar do século XXI, em especial o papel dos catadores e a efervescência da organização desses trabalhadores em cooperativas e associações nas últimas décadas". Tal articulação coletiva dos catadores tem propiciado maior valor ao seu trabalho e, assim, maior capacidade de mobilização frente às ações do poder público e da sociedade (SILVA; GOES; ALBINO, 2013).

Essas associações ou cooperativas, de acordo com Grimberg (2007, p. 77), apresentam algumas características comuns, que são dificultadoras para o seu gerenciamento, tais como: baixa escolaridade e/ou alto índice de analfabetismo, apontado como o principal complicador do processo de gestão e comunicação; incompreensão dos deveres e direitos de cada associado/cooperado; falta de conhecimento sobre a estrutura da atividade produtiva; alta rotatividade dos associados/cooperados, interferindo no fortalecimento de laços e na compreensão do que realmente seja um empreendimento autogestionário. Vale ressaltar que estas "[...] dificuldades levam os catadores a buscar soluções imediatas de resolução de suas carências individuais e familiares [...]" (SILVA; GOES; ALBINO, 2013, p. 21), em detrimento das necessidades do empreendimento, o que se revela como outro desafio para o grupo.

Além destes pontos, a gestão dessas Organizações de Catadores de Material Reutilizáveis e Recicláveis (OCMRR) enfrenta diversos desafios, dentre eles está a formalização de suas atividades. O SEBRAE aponta onze passos para a abertura formal de uma cooperativa (que em geral, seriam os mesmos trilhados para a constituição de uma associação), a saber:

\begin{abstract}
Elaborar o estatuto da cooperativa [...]; aprovar o estatuto em Assembleia Geral; registrar o estatuto em Cartório; registrar a cooperativa na Junta Comercial; Obter CNPJ no Ministério da Fazenda/Receita Federal; obter do Corpo de Bombeiros, laudo de exigências da localidade em que vai se estabelecer (nos estados onde tal exigência existir); obter a aquisição ou dispensa de registro estadual na Secretaria do Estado da Fazenda; realizar a inscrição no Instituto Nacional do Seguro Social - INSS; obter na Prefeitura a inscrição municipal e concessão de alvará de licença de funcionamento; procurar a Organização das Cooperativas do Estado (OCE), a fim de atender ao disposto no Art. 107 da Lei n. 5.764/71, integrando-se ao Cooperativismo Estadual e Nacional; é importante [ainda,] a aquisição e autenticação dos livros da cooperativa, como o de matrícula, de atas das assembleias gerais, de atas dos órgãos de administração, de atas do Conselho Fiscal, assim como seguir os procedimentos da localidade para a emissão de notas fiscais. (SEBRAE, 2017, p. 19-20).
\end{abstract}

Antes da formalização em si, tem-se que escolher sobre a melhor forma jurídica a atender o grupo de trabalho coletivo. Muñoz (2012) esclarece que associações e cooperativas são personalidades jurídicas que se diferenciam, já que associações são consideradas como empreendimentos coletivos de Sociedade Civil, enquanto as cooperativas são concebidas como Sociedade Mercantil.

Associação é constituída "pela união de pessoas que se organizem para fins não econômicos" (BRASIL, 2002, art. 53) e Muñoz (2012) aponta que um fator relevante é o número de participantes. Neste quesito, o autor adverte sobre um recorrente engano, pois a legislação estabelece que duas pessoas bastariam para que a associação fosse organizada, porém, na prática, "[...] esse número mínimo seria de dez pessoas, pois é o número necessário para preencher os cargos do Conselho de Administração e Conselho Fiscal que o Novo Código Civil exige que sejam formados" (MUÑOZ, 2012, p. 17). Já o conceito de cooperativa é expresso na Lei $\mathrm{n}^{\circ} 5.764$ de 1971, conhecida como a Política Nacional do Cooperativismo, a qual afirma que estas são "[...] sociedades de pessoas, com forma e natureza jurídica próprias, de natureza civil, não sujeitas a falência, constituídas para prestar serviços aos associados" e devem ser constituídas por mais de vinte trabalhadores. (BRASIL, 1971, artigos $4^{\circ}$ e $6^{\circ}$ ). 
Percebe-se, assim, que a fundação e a formalização desses empreendimentos, com as inúmeras etapas sinalizadas, apresentam um caminho complexo para esses grupos. Fora isso, há as necessidades estruturais, tais como: barracões com o mínimo de espaço e organização, maquinários, veículos, equipamentos de proteção individual, entre outros.

Porém, mesmo para "[...] aqueles que conseguem superar esses obstáculos [e exigências] iniciais com os 'custos do aprendizado' durante a formação do empreendimento" (SILVA; GOES; ALBINO, 2013, p. 21), existem ainda algumas adversidades relacionadas ao ambiente externo. Estas podem ser exemplificadas pela dificuldade de captação de crédito, quando não possui recurso próprio, que se faz necessário para realizar investimento em infraestrutura (como galpões), maquinários e/ou equipamentos (como prensas enfardadeiras, veículos, esteiras transportadoras, incineradores e outros).

Observa-se que, mesmo com as diferenças nas formas de organização e personalidade jurídica das associações/cooperativas em relação às empresas convencionais, as demandas para o funcionamento, no mercado, são comuns. As OCMRR necessitam, assim como as empresas convencionais, gerir o negócio em prol da sua sustentabilidade e dos envolvidos, recorrendo por vezes a recursos externos para investir. $E$, neste caso, assim como as empresas convencionais, as OCMRR demandam crédito no sistema financeiro. Sobre isto, Silva (2017) ressalta algumas situações observadas pelas OCMRR, evidenciando, especialmente, os empreendimentos de economia solidária (ESS). Destaca que

[...] os investimentos iniciais para a constituição da maior parte desses EES vêm de recursos próprios dos sócios (caso identificado em 33,9\% deles), principalmente no caso de empreendimentos informais, pouco estruturados. Nos outros casos, os recursos foram oriundos de fundos públicos não reembolsáveis, doação de pessoas físicas ou empresas, doação de organismos internacionais ou ONGs e, em menor parte, via empréstimos ou financiamentos bancários (apenas 2,7\%). Tal informação ilustra a dificuldade que esses EES possuem para obter crédito para suas atividades, muito em função da informalidade e da incapacidade de apresentarem garantias econômicas para linhas de financiamento bancário tradicionais. (SILVA, 2017, p. 35-36).

Dessa forma, faz-se necessário ponderar sobre uma possível exclusão financeira aos quais esses empreendimentos podem estar submetidos. A exclusão financeira é entendida a partir dos seguintes fatores: i) aspectos geográficos - infere-se que a localização das agências/instituições é um fator relevante; ii) avaliação de risco - são metodologias que categorizam e excluem clientes; iii) preço - taxas e custos que limitam o acesso à serviços financeiros (ou produtos, como também é chamado); iv) condicionantes (associados ao desenho e à disponibilização dos produtos) - a condição a qual um produto ofertado secciona certos grupos; v) marketing - segmentação de mercado feita pela condução da campanha publicitária; vi) complexidade para a escolha - a complexidade em si, seja pelos novos canais eletrônicos portáteis ou até mesmo pelos caixas eletrônicos; vii) auto exclusão - certos grupos se recusam a procurar tais serviços pois não se sentem identificados nesse sistema (LANA, 2013; CROCCO; SANTOS; FIGUEIREDO, 2013; SOUZA, 2015).

Silva (2017) salienta que existe dificuldade para a obtenção de crédito pelos empreendimentos, devido à situação de informalidade em que se encontram e por não possuírem garantias econômicas para oferecer como contrapartida.

[...] 82,0\% deles não buscaram crédito para suas atividades nos doze meses anteriores à pesquisa. Entre os demais, 10,2\% buscaram mas não obtiveram, e apenas $7,8 \%$ obtiveram algum tipo de crédito ou financiamento. Apesar disso, mais da metade dos EES de reciclagem (53,3\%) alegou necessitar de crédito, sobretudo para investimentos diversos nos empreendimentos. Em virtude dessa dificuldade de conseguir linhas de crédito, pouco mais da metade dos EES $(50,6 \%)$ conseguiu realizar algum tipo de investimento nos doze meses anteriores à pesquisa. As principais destinações para os investimentos realizados foram: aquisição ou renovação de equipamentos 
(46,3\%); melhorias de infraestrutura física (30,3\%); capacitação de mão de obra (12,8\%); e comunicação/divulgação (4,8\%). (SILVA, 2017, p. 36).

Frente ao exposto, surgem questões, tais como: o sistema financeiro tem interesse em suprir a demanda das OCMRR por crédito (empréstimos e financiamentos)? As suas linhas abrangem ou são adequadas a estes empreendimentos? Há outros meios de captação de recursos disponíveis no mercado, visto a condição de informalidade destes empreendimentos? Há exclusão financeira destas OCMRR?

Assim, este artigo objetiva identificar e analisar, no estado de São Paulo (SP), se os créditos (empréstimos ou financiamentos) ofertados pelas instituições financeiras $e$ as suas condições/exigências são adequadas à realidade das OCMRR. Este trabalho se justifica pela necessidade de conhecer, efetivamente, o que é oferecido a estas OCMRR, devido, principalmente, à relevância dessas organizações, tanto em âmbito nacional quanto no estado. De acordo com o Sistema Nacional de Informações sobre Saneamento (SNIS, 2018, n.p.), no ano de 2016, existiam 1.187 associações/cooperativas de catadores distribuídas em 812 municípios brasileiros, representando 26.775 catadores. Na mesma base, é possível identificar que o estado de São Paulo é o que possui o maior número de associações/cooperativas de catadores do país (236), o que representa $22,18 \%$ do total país, assim como o maior número de municípios (175) com organizações formalizadas e 6.460 trabalhadores envolvidos. Partindo destas informações, decidiu-se adotar como recorte geográfico o estado de São Paulo (SP).

\section{METODOLOGIA}

Com o intuito de realizar uma pesquisa exploratória, isto é, uma pesquisa que torna o problema explícito (TURRIONI e MELLO, 2012), foram realizadas coletas de dados das fontes de crédito disponíveis às OCMRR, no estado de São Paulo, em sites de instituições de diversas naturezas, como apresentado a seguir. Vale ressaltar que esta delimitação segue as orientações do Banco Central do Brasil (FURLANI, 2007). As instituições consideradas são:

(a) Principais instituições financeiras bancárias no país: Banco Bradesco, Banco Itaú Unibanco e Banco Santander. Estas três instituições são os maiores bancos (quantidade de ativo total dos balancetes e de agências) do Sistema Financeiro Nacional (BCB, 2017) e estão presentes no estado de São Paulo.

(b) Instituições financeiras de natureza especial: Banco do Brasil (BB), Caixa Econômica Federal (CEF) e Banco Nacional de Desenvolvimento Econômico e Social (BNDES) - os únicos que possuem atuação no estado.

(c) Instituições financeiras não-bancárias, especificamente agências de fomento ou desenvolvimento: no estado de São Paulo, a Fundação de Amparo à Pesquisa do Estado de São Paulo - FAPESP e a Agência de Desenvolvimento Paulista Desenvolve SP; e, de âmbito nacional e com atuação no estado, o Conselho Nacional de Desenvolvimento Científico e Tecnológico - CNPq e a Financiadora de Estudos e Projetos - FINEP. Opta-se por estas visto a relevância na área de fomento e desenvolvimento.

Além dessas instituições, foram consultados também os sites de instituições públicas relacionadas à temática dos resíduos sólidos, como: i) o Ministério do Meio Ambiente (MMA); ii) o Ministério do Trabalho e Previdência Social (MTPS); iii) o Ministério das Cidades (MCidades); iv) a Fundação Nacional de Saúde (FUNASA); v) o Banco do Povo Paulista (política pública de microcrédito produtivo do estado de SP); e, vi) o Fundo Estadual Científico e Tecnológico (Funcet).

Vale ressalvar que a escolha das instituições financeiras bancárias (item a) foi pautada não só na quantidade de ativos totais dos balancetes, mas também na quantidade de agências bancárias espalhadas pelo estado. Das agências bancárias no estado, 22,3\% são do Banco Bradesco, 17,1\% do Banco Itaú Unibanco e 19,9\% do Banco Santander, logo, juntas somam $59,3 \%$ das agências. Consideram-se ainda as agências do Banco do Brasil $(17,2 \%)$ e da Caixa 
Econômica Federal (13,6\%), os cinco bancos totalizam 90\% das agências bancárias do estado em dezembro de 2017. (BCB, 2018b).

A coleta de dados foi feita entre os anos de 2016 e 2017 e para cada instituição, que apresentava linha ou programa específico, são apontadas as principais características (facilidades/importâncias e dificuldades) dessa oferta, bem como a quantidade de OCMRR que obtiveram a concessão, quando houver esta informação disponibilizada pelas instituições. É importante destacar que os nomes de algumas instituições públicas utilizadas no período da coleta foram alterados recentemente, como o Ministério das Cidades que a partir de 2019 passa a ter a denominação de Ministério do Desenvolvimento Regional e o Ministério do Trabalho e Previsão Social se tornaram secretarias vinculadas ao Ministério da Economia. No entanto, as nomenclaturas aqui utilizadas fazem referência ao período da coleta.

Outra definição relevante para o trabalho refere-se à distinção entre empréstimo e financiamento. De acordo com o Banco Central do Brasil, empréstimo diz respeito a um "contrato entre o cliente e a instituição financeira pelo qual ele recebe uma quantia que deverá ser devolvida ao banco em prazo determinado, acrescida dos juros acertados. Os recursos obtidos no empréstimo não têm destinação específica" (BCB, 2018a, n.p.). Já financiamento, que também é um contrato entre cliente e instituição financeira, refere-se ao crédito com destinação específica, como a aquisição de um veículo ou de um bem imóvel e, para tal, busca-se algum tipo de garantia, como a alienação fiduciária ou hipoteca (BCB, 2018a).

\section{RESULTADOS E DISCUSSÃO INSTITUIÇÕES FINANCEIRAS BANCÁRIAS}

As instituições financeiras bancárias tradicionais atuantes no país apresentam, de maneira geral, diversas linhas de crédito destinadas às micros e pequenas empresas, tais como: capital de giro, antecipação de recebíveis, investimentos, entre outros (Quadro 1).

Quadro 1 - Tipos de linhas de crédito disponibilizadas nas principais instituições bancárias atuantes no estado de São Paulo, com seus valores mínimos e máximos de taxa de juros.

\begin{tabular}{|c|c|c|c|}
\hline $\begin{array}{l}\text { Tipo de Linha de } \\
\text { Crédito }\end{array}$ & Características & Taxa de Juros & $\begin{array}{c}\text { Condições de } \\
\text { Contratação }\end{array}$ \\
\hline Capital de Giro & $\begin{array}{c}\text { Crédito para suprir as } \\
\text { necessidades de caixa da } \\
\text { empresa. }\end{array}$ & $\begin{array}{c}\text { De } 18,14 \% \text { a } \\
104,45 \% \text { ao ano. }\end{array}$ & \multirow{3}{*}{$\begin{array}{l}\text { Contratações realizadas } \\
\text { na agência ou pela } \\
\text { internet. Apresentação de } \\
\text { garantias admitidas pelos } \\
\text { Bancos e compatíveis } \\
\text { com o instrumento de } \\
\text { crédito. Sujeito à } \\
\text { aprovação cadastral e de } \\
\text { crédito. }\end{array}$} \\
\hline $\begin{array}{l}\text { Antecipação de } \\
\text { Recebíveis }\end{array}$ & $\begin{array}{l}\text { Antecipação do valor das } \\
\text { vendas realizadas por meio de } \\
\text { títulos. }\end{array}$ & $\begin{array}{c}\text { De } 12,74 \% \text { a } \\
138,53 \% \text { ao ano. }\end{array}$ & \\
\hline Investimentos & $\begin{array}{l}\text { Crédito para financiar a } \\
\text { aquisição de equipamentos de } \\
\text { informática, máquinas e } \\
\text { equipamentos, material de } \\
\text { construção e veículos novos. }\end{array}$ & Negociáveis & \\
\hline
\end{tabular}

Nota - Estas informações são válidas, também, para as instituições de natureza especial, Banco Brasil e Caixa Econômica Federal.

Fonte - Elaborado a partir de BCB (2017, n.p.), CEF (2017, n.p.), BB (2017, n.p.), Santander (2017, n.p.), Itaú (2017a, n.p.) e Bradesco (2017, n.p.).

No Quadro 2 é possível observar o detalhamento de algumas das linhas de empréstimo e financiamento ofertadas para Investimento pelas instituições bancárias Bradesco, Santander e Itaú Unibanco. 
Quadro 2 - Linhas de crédito ofertadas pelo Bradesco, Itaú Unibanco e Santander, para pequenas e médias empresas, em 2017.

\begin{tabular}{|c|c|c|c|c|}
\hline INSTITUIÇÃO & PRODUTO & $\begin{array}{l}\text { TAXA DE } \\
\text { JUROS }\end{array}$ & PRAZO & $\begin{array}{l}\text { CONDIÇÕES DE } \\
\text { CONTRATAÇÃO }\end{array}$ \\
\hline \multirow{6}{*}{$\begin{array}{l}\text { O } \\
\mathscr{d} \\
\frac{0}{0} \\
\frac{\pi}{0}\end{array}$} & $\begin{array}{c}\text { Cred } \\
\text { Investimento }\end{array}$ & $\begin{array}{c}\text { Juros + Tarifa }+ \\
\text { IOF }\end{array}$ & De 37 a 60 meses. & $\begin{array}{l}\text { Alienação de bens móveis e } \\
\text { imóveis; cessão fiduciária de } \\
\text { duplicatas e cheques; } \\
\text { aplicação financeira; e aval. }\end{array}$ \\
\hline & $\begin{array}{c}\text { Compror } \\
\text { Estoque Fácil }\end{array}$ & $\begin{array}{c}\text { Juros }+ \text { Tarifa }+ \\
\text { IOF }\end{array}$ & $\begin{array}{l}\text { Limite de até } 180 \text { dias; } \\
\text { Pagamento Único de até } \\
90 \text { dias; ou Parcelado de } \\
\text { até } 13 \text { meses. }\end{array}$ & $\begin{array}{c}\text { Aval e outras, a critério do } \\
\text { banco. }\end{array}$ \\
\hline & $\begin{array}{l}\text { CDC Flex } \\
\text { Bradesco }\end{array}$ & $\begin{array}{l}\text { Juros } 2,9 \% \text { a.m. } \\
+ \text { Tarifa } 30 \% \text { de } \\
\text { entrada + IOF }\end{array}$ & $\begin{array}{c}\text { Até } 48 \text { meses para pagar. } \\
\text { Carência de } 15 \text { a } 59 \text { dias } \\
\text { para a } 1^{\text {a }} \text { parcela. }\end{array}$ & $\begin{array}{l}\text { Alienação do bem, aval ou nota } \\
\text { promissória. Disponível para } \\
\text { correntistas com idade mínima } \\
\text { de } 18 \text { anos, desde que o bem } \\
\text { esteja em perfeitas condições } \\
\text { de uso e conservação. }\end{array}$ \\
\hline & $\begin{array}{l}\text { CDC Outros } \\
\text { Bens }\end{array}$ & $\begin{array}{l}\text { Juros de } 3,3 \% \\
\text { a.m. + Tarifa } 30 \% \\
\text { de entrada + IOF }\end{array}$ & De 1 a 48 meses. & $\begin{array}{l}\text { Alienação do bem, aval ou nota } \\
\text { promissória. Disponível para } \\
\text { correntistas com idade mínima } \\
\text { de } 18 \text { anos, desde que o bem } \\
\text { esteja em perfeitas condições } \\
\text { de uso e conservação. }\end{array}$ \\
\hline & $\begin{array}{l}\text { Leasing Outros } \\
\text { Bens }\end{array}$ & $\begin{array}{l}\text { Juros + Tarifa } \\
2,5 \% \text { do valor do } \\
\text { contrato }\end{array}$ & $\begin{array}{c}\text { Mínimo para } \\
\text { Computadores e periféricos } \\
\text { de } 24 \text { meses; Máquinas e } \\
\text { equipamentos de } 36 \\
\text { meses. Prazo máximo de } \\
60 \text { meses. }\end{array}$ & Nota promissória, aval e outras. \\
\hline & $\begin{array}{l}\text { Microcrédito } \\
\text { Produtivo } \\
\text { Orientado }\end{array}$ & Taxas Atrativas & Não mencionado. & $\begin{array}{l}\text { Limites de pagamento de } \\
\text { acordo com a capacidade do } \\
\text { empreendimento. Sujeito à } \\
\text { aprovação do banco. }\end{array}$ \\
\hline \multirow{3}{*}{ 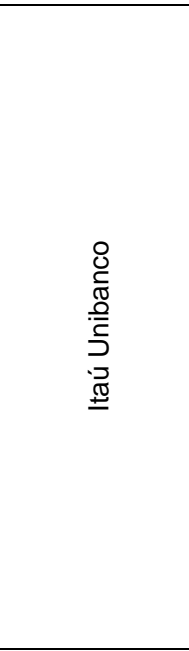 } & $\begin{array}{l}\text { CDC - Crédito } \\
\text { Direto ao } \\
\text { Cliente } \\
\end{array}$ & $\begin{array}{c}\text { Taxas Pré- } \\
\text { fixadas + Tarifas } \\
+ \text { IOF } \\
\end{array}$ & $\begin{array}{l}\text { Conforme a necessidade } \\
\text { da empresa, sendo o } \\
\text { máximo } 48 \text { meses. }\end{array}$ & $\begin{array}{c}\text { Garantias dos próprios bens } \\
\text { adquiridos. Sujeito à aprovação } \\
\text { de crédito. }\end{array}$ \\
\hline & Leasing & $\begin{array}{c}\text { Taxas pré-fixadas } \\
\text { ou indexadas ao } \\
\text { CDI }\end{array}$ & $\begin{array}{c}\text { Pagamento da primeira } \\
\text { parcela em até } 180 \text { dias. } \\
\text { Mínimo de } 24 \text { meses para } \\
\text { bens com vida útil de até } 5 \\
\text { anos e de } 36 \text { meses para } \\
\text { bens com vida útil superior } \\
\text { a } 5 \text { anos. O prazo máximo } \\
\text { está limitado à aprovação } \\
\text { de crédito. }\end{array}$ & $\begin{array}{c}\text { Garantias dos próprios bens } \\
\text { adquiridos. Sujeito à aprovação } \\
\text { de crédito. }\end{array}$ \\
\hline & Microcrédito & $\begin{array}{c}\text { 3,99\% a.m. }+3 \% \\
\text { do valor do } \\
\text { contrato - taxa de } \\
\text { abertura de } \\
\text { crédito }\end{array}$ & $\begin{array}{c}\text { De } 4 \text { a } 7 \text { parcelas na } \\
\text { primeira contratação e de } 4 \\
\text { a } 15 \text { parcelas na } \\
\text { renovação, dependendo da } \\
\text { finalidade do crédito. }\end{array}$ & $\begin{array}{l}\text { A análise é feita por um agente } \\
\text { de microcrédito do banco, que } \\
\text { visita o empreendimento ou } \\
\text { local de trabalho. O agente } \\
\text { orienta o planejamento e a } \\
\text { aplicação do crédito de acordo } \\
\text { com as necessidades } \\
\text { financeiras do negócio. }\end{array}$ \\
\hline \multirow{4}{*}{ 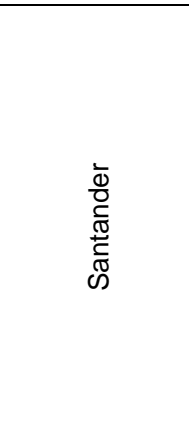 } & $\begin{array}{l}\text { Financiamento } \\
\text { de Veículos }\end{array}$ & $\begin{array}{l}\text { Taxa de Juros + } \\
\text { Tarifa + IOF }\end{array}$ & $\begin{array}{c}\text { De até } 60 \text { meses para } \\
\text { finalização do pagamento. } \\
\text { E de até } 59 \text { dias para pagar } \\
\text { a primeira parcela. }\end{array}$ & \multirow{4}{*}{$\begin{array}{l}\text { Sujeito à análise de crédito e } \\
\text { às demais condições do } \\
\text { produto no momento da } \\
\text { contratação. É necessário ser } \\
\text { correntista. }\end{array}$} \\
\hline & $\begin{array}{l}\text { Leasing de } \\
\text { Veículos }\end{array}$ & $\begin{array}{l}\text { ISS + Tarifa + } \\
\text { Taxa de Juros }\end{array}$ & De 24 a 60 meses. & \\
\hline & $\begin{array}{l}\text { Financiamento } \\
\text { de Máquinas e } \\
\text { Equipamentos }\end{array}$ & $\begin{array}{l}\text { Taxa de Juros + } \\
\text { Tarifa + IOF }\end{array}$ & $\begin{array}{c}\text { De até } 48 \text { meses para } \\
\text { pagar. }\end{array}$ & \\
\hline & $\begin{array}{l}\text { Leasing de } \\
\text { Máquinas e } \\
\text { Equipamentos }\end{array}$ & $\begin{array}{l}\text { ISS + Tarifa + } \\
\text { Taxa de Juros }\end{array}$ & $\begin{array}{l}\text { De } 24 \text { a } 48 \text { meses para } \\
\text { pagar, de acordo com as } \\
\text { regras de vida útil do bem. }\end{array}$ & \\
\hline
\end{tabular}

Fonte - Elaborado a partir de Bradesco (2017, n.p.), Itaú (2017a, n.p.) e Santander (2017, n.p.). 
Além das linhas convencionais, identificam-se algumas oportunidades de apoio de crédito. Neste ínterim, o Banco Santander ofereceu, de 2005 a 2015, recursos através de uma premiação para apoio financeiro no valor de $R \$ 100$ mil para cada projeto escolhido e que abrangia, dentre outros, o ramo da coleta seletiva, denominado Prêmio Santander Universidade Solidária. Esta premiação objetivava "[...] promover a troca entre ensino e a pesquisa acadêmica e o saber popular de modo a contribuir para a inclusão social e econômica de comunidades e para a formação cidadã do futuro profissional" (SANTANDER UNIVERSIDADES, 2016, n.p.). Neste prêmio, foram contempladas as seguintes OCMRR do estado de SP: Cooperlix (Presidente Prudente) em 2010, Coocassis (Assis) em 2011 e Coopervida (São Carlos) no ano de 2015. Esse projeto não se configura como uma linha crédito convencional, e sim como apoio financeiro. É importante ressaltar que, nestes casos, as Organizações ficavam dependentes das Universidades para a realização de projetos.

O Banco Itaú Unibanco, em parceria com o Instituto Ekos Brasil, desde 2009, oferece o Programa Ecomudança, que premia com apoio financeiro de até $R \$ 100$ mil os projetos selecionados. O Programa contempla entidades sem fins lucrativos - organizações sociais, fundações, associações e cooperativas, inclusive as que atuam como movimentos sociais nas modalidades: "Eficiência Hídrica, Eficiência Energética, Manejo de Resíduos, Floresta, Agricultura Sustentável e Mobilidade.". O valor deste apoio vem dos fundos de renda fixa Ecomudança Itaú, que destina 30\% das taxas de administração ao programa. (ITAÚ, 2017b, n.p.).

O Banco Bradesco, apesar de ofertar empréstimos e financiamentos para pequenas e médias empresas (Quadro 1 e 2), não possui programas específicos para resíduos sólidos.

Percebe-se que, no caso do Prêmio oferecido pelo Santander Universidades, os recursos são oferecidos, através de intermediários, às Instituições de Ensino. O Programa Ecomudança do Banco Itaú Unibanco, por sua vez, não define a necessidade de se estabelecer vínculo com terceiros, porém o processo de preenchimento dos formulários é apenas online, o que por si só já é um complicador, visto que não há tutoriais ou informações sobre o preenchimento.

De forma geral, as três instituições bancárias ofertam crédito para micro e pequenas empresas, com condições de difícil acesso às OCMRR, pois são linhas abrangentes e tradicionais que objetivam atender o maior número de demandantes (clientes) e que, por isso, exigem garantias, avalistas, altas taxas de juros, encargos e outros.

Em outras palavras, pode-se dizer que existe exclusão financeira, pois ao se considerar que a exclusão financeira está relacionada à falta de conta corrente ou serviço bancário adequado aos indivíduos (SIMPSON e BUCKLAND, 2016), pressupõe-se a existência de uma agência bancária ou outro instrumento que permita a realização deste serviço. Porém, verifica-se, na situação das OCMRR, que a captação de crédito através de empréstimos ou financiamentos é de difícil ocorrência nos meios tradicionais de intermediação (agências bancárias, postos de atendimento ou correspondentes bancários), vistos as condições exigidas, o que favorece a busca de captação em outras instituições e por outros meios (prêmios, programas ou apoio financeiro em geral). Mesmo neste último caso, as OCMRR podem ficar dependentes da relação com outras entidades (Instituições de Ensino), o que as mantêm à margem do processo de intermediação financeira.

\section{INSTITUIÇÕES FINANCEIRAS DE NATUREZA ESPECIAL}

As instituições financeiras de natureza especial seguem a mesma lógica das instituições financeiras bancárias. Apesar do caráter "público" que apresentam parcialmente (Banco do Brasil) ou integralmente (Caixa Econômica Federal), a exclusão financeira ainda prevalece, visto as principais linhas de empréstimos e financiamentos ofertadas (Quadro 3). 
Quadro 3 - Linhas de crédito para investimento do Banco do Brasil e da Caixa Econômica Federal, em

\begin{tabular}{|c|c|c|c|c|}
\hline \multicolumn{5}{|c|}{2017.} \\
\hline INSTITUIÇÃO & PRODUTO & TAXA DE JUROS & PRAZO & CONDIÇÕES DE CONTRATAÇÃO \\
\hline \multirow{4}{*}{ 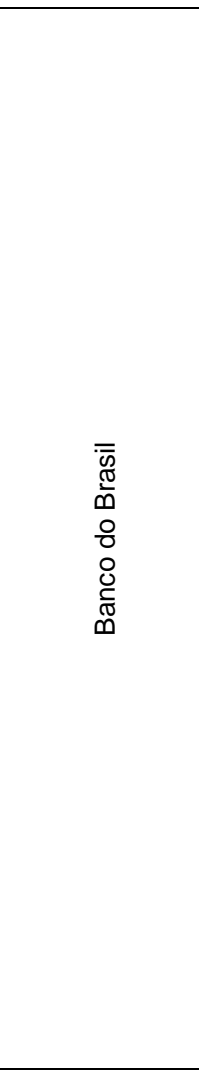 } & $\begin{array}{l}\text { Proger Urbano } \\
\text { Empresarial }\end{array}$ & $\begin{array}{l}\text { As taxas variam de } \\
\text { acordo com o } \\
\text { relacionamento } \\
\text { com o Banco do } \\
\text { Brasil. }\end{array}$ & $\begin{array}{c}\text { De até } 72 \text { meses, } \\
\text { com até } 12 \text { meses } \\
\text { para pagar a primeira } \\
\text { parcela. }\end{array}$ & $\begin{array}{c}\text { Empresas que faturam até } \mathrm{R} \$ 10 \\
\text { milhões por ano; valor máximo } \\
\text { requerido de } \mathrm{R} \$ 1 \text { milhão e que seja } \\
\text { utilizado para geração ou } \\
\text { manutenção de emprego e renda; } \\
\text { depende de aprovação de cadastro e } \\
\text { crédito. } \\
\end{array}$ \\
\hline & $\begin{array}{l}\text { BB Crédito } \\
\text { Empresa }\end{array}$ & \begin{tabular}{|c|} 
As taxas variam de \\
acordo com o \\
relacionamento \\
com o Banco do \\
Brasil. \\
\end{tabular} & $\begin{array}{l}\text { De até } 60 \text { meses } \\
\text { para pagamento. }\end{array}$ & $\begin{array}{c}\text { Empresas com faturamento bruto } \\
\text { anual de até } \mathrm{R} \$ 90 \text { milhões e que } \\
\text { demandem no mínimo } \mathrm{R} \$ 1 \text { mil de } \\
\text { financiamento; depende de } \\
\text { aprovação de cadastro e crédito. } \\
\end{array}$ \\
\hline & Leasing & $\begin{array}{c}\text { Definida de acordo } \\
\text { com o percentual } \\
\text { de Valor Residual } \\
\text { Garantido (VRG) } \\
\text { pago } \\
\text { antecipadamente, } \\
\text { diluído ou no final } \\
\text { da operação. }\end{array}$ & \begin{tabular}{|c|} 
O pagamento deve \\
ocorrer entre 24 ou \\
36 meses, de acordo \\
com a vida útil fiscal \\
do bem arrendado. O \\
cliente é quem \\
escolhe a forma de \\
pagamento mais \\
adequada ao fluxo de \\
caixa da sua \\
empresa. \\
\end{tabular} & $\begin{array}{l}\text { Cadastro atualizado da empresa; } \\
\text { limite de crédito disponível; proposta } \\
\text { de aquisição do bem a ser } \\
\text { arrendado. }\end{array}$ \\
\hline & $\begin{array}{l}\text { Microcrédito } \\
\text { Produtivo } \\
\text { Orientado }\end{array}$ & $\begin{array}{l}\text { As taxas variam de } \\
\text { acordo com o } \\
\text { relacionamento } \\
\text { com o Banco do } \\
\text { Brasil. }\end{array}$ & $\begin{array}{c}\text { De } 4 \text { a } 12 \text { parcelas, } \\
\text { para operações para } \\
\text { capital de giro. De } 4 \text { a } \\
18 \text { parcelas, para } \\
\text { investimento. }\end{array}$ & $\begin{array}{c}\text { Ser correntista e microempreendedor } \\
\text { individual (MEI), com faturamento até } \\
\mathrm{R} \$ 60 \text { mil por ano ou microempresa } \\
\text { que fatura até } \mathrm{R} \$ 120 \text { mil por ano; ter } \\
\text { garantia pessoal de terceiros, o que } \\
\text { pode ser dispensada; não estar } \\
\text { endividado no Sistema Financeiro } \\
\text { Nacional acima } \mathrm{R} \$ 40 \text { mil; solicitação } \\
\text { deverá ter aprovação de cadastro e } \\
\text { crédito. } \\
\end{array}$ \\
\hline \multirow{4}{*}{ 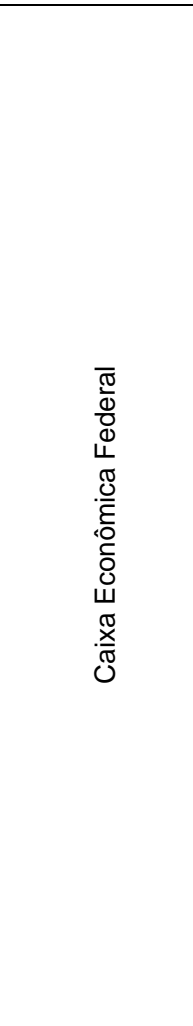 } & $\begin{array}{l}\text { Bens de } \\
\text { Consumo } \\
\text { Duráveis }\end{array}$ & $\begin{array}{l}\text { Juros pós-fixados, } \\
\text { com correção pela } \\
\text { TR + IOF + Tarifas. }\end{array}$ & $\begin{array}{l}\text { O pagamento pode } \\
\text { ser feito em até } 60 \\
\text { meses, incluído o } \\
\text { período de carência } \\
\text { de até seis meses. }\end{array}$ & $\begin{array}{l}\text { "Cédula de Crédito Bancário (CCB), } \\
\text { emitida pelo tomador em favor da } \\
\text { Caixa, avalizada pelos sócios } \\
\text { dirigentes da empresa; alienação } \\
\text { fiduciária dos bens financiados. } \\
\text { Podem ser solicitadas garantias } \\
\text { adicionais, se necessário. Os bens } \\
\text { constitutivos da garantia em favor da } \\
\text { Caixa devem ser cobertos por } \\
\text { seguro, conforme o tipo do bem, } \\
\text { durante toda a vigência do contrato." }\end{array}$ \\
\hline & $\begin{array}{l}\text { PROGER } \\
\text { Investgiro }\end{array}$ & Juros + Tarifas & \begin{tabular}{|c|} 
De até 60 meses, \\
incluindo carência de \\
até 12 meses (a \\
depender da \\
disponibilidade de \\
recursos do FAT). \\
\end{tabular} & $\begin{array}{l}\text { Ser empresa cliente; ter cadastro } \\
\text { aprovado e capacidade de } \\
\text { pagamento. }\end{array}$ \\
\hline & $\begin{array}{l}\text { Financiamento } \\
\text { de Veículo - } \\
\text { CREDFROTA }\end{array}$ & $\begin{array}{l}\text { Taxa de juros pré- } \\
\text { fixada (SAC). }\end{array}$ & \begin{tabular}{|l|} 
Para pagamento do \\
empréstimo é de até \\
24 meses para \\
empresas locadoras \\
de veículos e de até \\
60 meses para as \\
demais empresas. \\
\end{tabular} & $\begin{array}{l}\text { Ser aprovado na avaliação cadastral } \\
\text { e ter capacidade de pagamento }\end{array}$ \\
\hline & $\begin{array}{l}\text { Microcrédito } \\
\text { Produtivo } \\
\text { Orientado }\end{array}$ & \begin{tabular}{|c|} 
Taxa de Juros de \\
$2,95 \%$ ao mês + \\
IOF + Taxa de \\
Abertura de Credito \\
de $3 \%$ sobre o \\
valor do contrato.
\end{tabular} & \begin{tabular}{|c|} 
De 04 a 24 meses. \\
Para primeira \\
contratação o prazo é \\
de até 12 meses para \\
pagar, dependendo \\
da finalidade do \\
crédito.
\end{tabular} & $\begin{array}{l}\text { Idade do demandante superior a } 18 \\
\text { anos ou emancipado; ter conta na } \\
\text { Instituição; não estar em cadastros } \\
\text { de inadimplência; ter avalista se for o } \\
\text { caso. "O valor do crédito depende da } \\
\text { análise do crédito e da capacidade } \\
\text { de pagamento do empreendimento." }\end{array}$ \\
\hline
\end{tabular}

Fonte - Elaborado a partir de BB (2017, n.p.) e CEF (2017, n.p.). 
Vale destacar que as linhas PROGER Urbano Empresarial do Banco do Brasil, PROGER Investgiro e Microcrédito Produtivo Orientado, ambos da Caixa Econômica Federal (Quadro 3), possuem subsídios do governo federal através do Fundo de Amparo ao Trabalhador - FAT. Estas linhas são parte de uma política pública que visa fomentar microempreendedores populares, formais e informais, com intuito de gerar trabalho e renda (FAT, 2016, n.p.). Porém, identifica-se que a linha do Banco do Brasil financia apenas $80 \%$ do valor requerido para financiamento, logo os requerentes (OCMRR) devem possuir os outros $20 \%$. O PROGER Investgiro exige, em uma das etapas de aprovação, um Plano de Negócios elaborado pelos requerentes do crédito, o que requer estudos do negócio, abordagens metodológicas que fogem da realidade dos empreendimentos. Já o Microcrédito Produtivo Orientado da Caixa é o que possui maior acessibilidade às OCMRR, não fossem as elevadas taxas, conforme demonstrado no Quadro 3.

Apesar das impossibilidades de acesso às linhas de crédito tradicionais destes bancos, estes oferecem outras fontes de obtenção de recursos, como apresentado no Quadro 4. Uma destas fontes é o Projeto Cataforte, do Banco do Brasil, que iniciou em 2007, com o intuito de "[...] contribuir para a constituição e fortalecimento de empreendimentos econômicos solidários constituídos por catadores e catadoras de materiais recicláveis" (FBB, 2016, n.p.). O Projeto Cataforte é uma política pública e não se categoriza como uma linha de crédito através de empréstimos e/ou financiamentos, os quais podem ser requisitados a qualquer momento, visto que este Projeto depende da abertura de edital. Essa importante política promove a captação de recursos pelas OCMRR no país e, também, no estado de SP, através de concessão de recursos financeiros para a formação dos catadores, assistência técnica às associações/ cooperativas, além de contribuir na elaboração de projetos para estruturação de redes e no fortalecimento da infraestrutura destas redes e suas logísticas. Já foram realizados três programas dentro do Projeto Cataforte, que possibilitaram o atendimento de 70 associações e cooperativas no estado de SP através da atuação em redes, de 2010 a 2013.

Quadro 4 - Programas de financiamento do Banco do Brasil e da Caixa Econômica Federal.

\begin{tabular}{|c|c|c|c|}
\hline INSTITUIÇÃO & $\begin{array}{c}\text { LINHAS DE } \\
\text { FINANCIAMENTO/ } \\
\text { PROJETOS }\end{array}$ & $\begin{array}{c}\text { OUTRAS INSTITUIÇÕES } \\
\text { ENVOLVIDAS }\end{array}$ & $\begin{array}{c}\text { FONTE DE } \\
\text { RECURSOS }\end{array}$ \\
\hline Banco do Brasil & Projeto Cataforte & $\begin{array}{c}\text { MNCR }^{1} \text {; BNDES; Petrobrás; SENAES } \\
\text { MTPS }^{3} ; \text { Governo Federal }\end{array}$ & Não cita \\
\hline $\begin{array}{c}\text { Caixa } \\
\text { Fonômica }\end{array}$ & $\begin{array}{c}\text { Programa Resíduos } \\
\text { Sólidos Urbanos }\end{array}$ & Ministério das Cidades & $\begin{array}{c}\text { Orçamento Geral } \\
\text { da União (OGU) }\end{array}$ \\
\hline
\end{tabular}

${ }^{1}$ MNCR - Movimento Nacional de Catadores de Materiais Recicláveis. ${ }^{2}$ SENAES - Secretaria Nacional de Economia Solidária.

Fonte - Elaborado a partir de BB (2017, n.p.) e CEF (2017, n.p.).

Além desse projeto, a Fundação Banco do Brasil, abriu edital em 2017 para Seleção Pública de Propostas de Patrocínios para eventos, em prol das organizações da sociedade civil. O apoio financeiro variou de $R \$ 30$ mil a $R \$ 100$ mil, contemplando eventos que deveriam ocorrer, entre $1^{\circ}$ de junho a 31 de dezembro de 2017, nas seguintes áreas: agroindústria, agroecologia, água, educação, resíduos sólidos e tecnologia social (ABCR, 2017).

Na Caixa Econômica Federal, há o Programa "Resíduos Sólidos Urbanos", que é promovido pelo Ministério das Cidades, para "[...] apoio a Sistemas Públicos de Manejo de Resíduos Sólidos em municípios com população superior a 50 mil habitantes ou municípios integrantes de regiões metropolitanas ou de Regiões Integradas de Desenvolvimento" (MCidades, 2012, p. 1). O programa incentiva a adoção de boas práticas no tratamento de resíduos sólidos através das seguintes modalidades: i) desativação de lixões existentes; ii) implantação ou adequação de sistemas de acondicionamento, coleta e separação dos RS; iii) implantação ou adequação de sistemas de tratamento; iv) implantação de estações de transbordo; e, v) implantação ou adequação dos sistemas de coleta, triagem e acondicionamento de resíduos de construção e demolição. Porém, o programa é destinado exclusivamente ao Poder Público Municipal, cabendo ao mesmo a execução dessas modalidades, da forma que Ihe for conveniente, não 
explicitando o incentivo ou o apoio às OCMRR já existentes nos municípios. Vale destacar, ainda, que exclui 521 municípios de um total de 645 municípios do estado de SP, por estes não terem mais de 50 mil habitantes, dados do Censo Demográfico de 2010 (IBGE, 2016).

O BNDES é uma instituição financeira de esfera Federal, responsável pela política de crédito de longo prazo. As formas de obtenção do crédito existentes no banco são: direta quando o requerente se relaciona diretamente com o BNDES; e indireta quando tem uma instituição intermediando, podendo esta ser uma instituição bancária, instituição de serviço especial, dentre outras (BNDES, 2017, n.p.).

Além disso, os recursos podem ser cedidos aos requerentes de forma não reembolsável e reembolsável. Os recursos não reembolsáveis, de acordo com o BNDES (2017, n.p.), são os "recursos financeiros utilizados para apoio de projetos sem a exigência de pagamento [de custos financeiros e taxas de juros] ao BNDES", enquanto os recursos de natureza reembolsável requerem amortização e pagamento de juros. São ofertados direta ou indiretamente e orientados a pessoas físicas e jurídicas empreendedoras, inclusive, de atividades de micro e pequeno porte. Além do custo, há linhas que exigem projeto formalizado dentro de normas pré-definidas, o que pode inviabilizar a tomada deste crédito pelas OCMRR, devido à baixa escolaridade de seus integrantes (GRIMBERG, 2007). Com o olhar apenas nos custos das transações, percebe-se que projetos com recursos não reembolsáveis seriam os melhores para a condição das OCMRR, porém a necessidade de preenchimento de inúmeros formulários, informativos e a confecção de projetos é um limitador.

O BNDES traz, entre várias formas de crédito, linhas e programas exclusivos para organizações de cunho social. Estes recursos compreendem organizações não só de caráter social, mas também de cunho cultural (ensino e pesquisa), ambiental, científico ou tecnológico. O foco destas ofertas de recursos, para apoio Social, é atender projetos produtivos coletivos, em prol de desenvolvimento regional e social com o objetivo de "[...] geração de trabalho e renda para populações de baixa renda, nos setores agropecuário, industrial, de comércio e de serviços". (BNDES, 2017, n.p.). Eles podem ser demandados por cooperativas, pessoas físicas e jurídicas, nas formas de apoio direta e indireta, desde que atendam o exigido (Quadro 5).

\begin{tabular}{|c|c|c|c|c|}
\hline $\begin{array}{c}\text { LINHAS E } \\
\text { PROGRAMAS } \\
\end{array}$ & $\begin{array}{c}\text { FORMA DE } \\
\text { APOIO }\end{array}$ & $\begin{array}{c}\text { REEMBOLSÁVEL } \\
\text { OU NÃO }\end{array}$ & PÚBLICO-ALVO & VIGÊNCIA \\
\hline $\begin{array}{l}\text { BNDES Microcrédito } \\
\text { - Empreendedor }\end{array}$ & Indireta & Reembolsável & $\begin{array}{c}\text { "Pessoas físicas e jurídicas } \\
\text { empreendedoras de atividades produtivas } \\
\text { de pequeno porte, ou seja, aquelas que } \\
\text { obtenham receita bruta igual ou inferior a } \\
\mathrm{R} \$ 360 \text { mil em cada ano-calendário." }\end{array}$ & Em vigor* \\
\hline $\begin{array}{l}\text { Programa de apoio à } \\
\text { consolidação de } \\
\text { empreendimentos } \\
\text { autogestionários - } \\
\text { PACEA }\end{array}$ & $\begin{array}{l}\text { Direta e } \\
\text { indireta }\end{array}$ & Reembolsável & $\begin{array}{c}\text { "Cooperativas de produção, centrais ou } \\
\text { singulares, que apresentem as seguintes } \\
\text { características: serem autogestionárias, } \\
\text { ou seja, apresentarem uma gestão } \\
\text { participativa e democrática, em que todos } \\
\text { os cooperados têm acesso às } \\
\text { informações referentes à gestão do } \\
\text { empreendimento; constituídas a partir de } \\
\text { situações de falência ou fechamento de } \\
\text { unidades produtivas que utilizem a } \\
\text { estrutura de produção do antecessor; } \\
\text { atuação em segmentos industriais; } \\
\text { quantitativo de trabalhadores não } \\
\text { associados não superior a 50\% de seu } \\
\text { quadro de pessoal (percentual não inclui } \\
\text { os terceirizados); e valor da maior retirada } \\
\text { não superior a } 10 \text { vezes o valor da } \\
\text { menor.” }\end{array}$ & $\begin{array}{l}\text { Expirada (até } \\
\text { 2013) }\end{array}$ \\
\hline
\end{tabular}

Fonte - Elaborado a partir de BNDES (2017, n.p.).

$\begin{array}{llllll}\text { Caminhos de Geografia } & \text { Uberlândia - MG } & \text { v. 20, n. } 70 & \text { Junho/2019 } & \text { p. 158-178 } & \text { Página } 167\end{array}$


A linha "BNDES Microcrédito - Empreendedor" oferece financiamentos de até R\$20 mil a microempreendedores formais e informais, com $100 \%$ do valor financiado. De acordo com o BNDES (2017), as taxas de juros (não podendo passar de 4\% ao mês, considerando-se já todos os encargos), os prazos e as garantias são negociados pelo cliente diretamente com o agente operador. Não são exigidas garantias reais, já que a maioria das transações tem como garantia o aval solidário. Este financiamento mostra-se viável aos requerentes das OCMRR, visto que, no estado de SP, identifica-se o Banco do Povo - Crédito Solidário de Santo André cadastrado para tal movimentação de recursos (créditos de até $R \$ 20$ mil). No entanto, apenas as OCMRR localizadas na região próxima de atendimento deste Banco possuem oportunidade de requerer esse crédito, o que é um dos pontos abordados na exclusão financeira. Vale ressaltar que o Banco do Povo - Crédito Solidário de Santo André surgiu como uma ONG após parceria da prefeitura local, sindicatos e associações e a sua atuação abrange mais quatro municípios (Mauá, Ribeirão Pires, Diadema e São Bernardo dos Campos) (BPCS, 2017).

O "Programa de apoio à consolidação de empreendimentos autogestionários - PACEA" financia até $R \$ 30$ milhões para cooperativas realizarem empreendimentos autogestionários e sustentáveis no setor industrial. Há custos e incidência de taxa de juros sobre o financiamento. Porém, o Programa está com prazo de vigência expirado e não recebe mais pedidos de financiamento.

Além da área Social, tem-se financiamento para as áreas de Meio Ambiente ou Infraestrutura, entre outras (Quadro 6).

Quadro 6 - Outras linhas de crédito oferecidas pelo BNDES

\begin{tabular}{|c|c|c|c|c|}
\hline $\begin{array}{c}\text { LINHAS E } \\
\text { PROGRAMAS DE } \\
\text { FINANCIAMENTO }\end{array}$ & $\begin{array}{l}\text { FORMA } \\
\text { DE } \\
\text { APOIO }\end{array}$ & $\begin{array}{c}\text { REEMBOLSÁVEL } \\
\text { OU NÃO }\end{array}$ & PÚBLICO-ALVO & VIGÊNCIA \\
\hline $\begin{array}{l}\text { BNDES Finem: } \\
\text { Saneamento } \\
\text { Ambiental e } \\
\text { Recursos Hídricos }\end{array}$ & $\begin{array}{l}\text { Direta ou } \\
\text { Indireta }\end{array}$ & Reembolsável & $\begin{array}{l}\text { Pessoa jurídica de direito } \\
\text { público, pessoa jurídica de } \\
\text { direito privado com sede e } \\
\text { administração no país e } \\
\text { empresário individual. }\end{array}$ & Em vigor \\
\hline $\begin{array}{c}\text { BNDES Finem: Meio } \\
\text { Ambiente }\end{array}$ & $\begin{array}{l}\text { Direta ou } \\
\text { Indireta }\end{array}$ & Reembolsável & $\begin{array}{l}\text { Sociedades com sede e } \\
\text { administração no país, de } \\
\text { controle nacional ou } \\
\text { estrangeiro; empresários } \\
\text { individuais; associações e } \\
\text { fundações; e pessoas } \\
\text { jurídicas de direito público. }\end{array}$ & Em vigor \\
\hline $\begin{array}{l}\text { BNDES Finem - } \\
\text { Desenvolvimento } \\
\text { integrado dos } \\
\text { municípios }\end{array}$ & $\begin{array}{l}\text { Direta ou } \\
\text { Indireta }\end{array}$ & Reembolsável & $\begin{array}{l}\text { "Entidades e órgãos } \\
\text { públicos; empresas com } \\
\text { sede e administração no } \\
\text { país; empresário individual } \\
\text { com CNPJ regularmente } \\
\text { constituído." }\end{array}$ & Em vigor \\
\hline BNDES Proplástico & $\begin{array}{l}\text { Direta ou } \\
\text { Indireta }\end{array}$ & Reembolsável & $\begin{array}{l}\text { Empresas de cadeia } \\
\text { produtiva do plástico, } \\
\text { como produtor, fornecedor } \\
\text { de equipamentos, } \\
\text { reciclador ou distribuidor; } \\
\text { setor de transformados } \\
\text { plásticos; distribuidores de } \\
\text { resina; empresas de } \\
\text { reciclagem; máquinas e } \\
\text { equipamentos; moldes. }\end{array}$ & Expirada (até 2017) \\
\hline
\end{tabular}

Fonte - Elaborado a partir de BNDES (2017, n.p.).

A linha de crédito BNDES "Finem - Saneamento Ambiental e Recursos Hídricos" visa o acesso aos serviços de saneamento básico e a recuperação de áreas ambientalmente degradadas. É destinada a projetos acima de $\mathrm{R} \$ 20$ milhões e tem a incidência de taxa de juros e custos bancários, porém apenas $80 \%$ dos valores dos itens são financiados. 
A Linha "Finem - Meio Ambiente" abrangia vários setores da cadeia dos resíduos sólidos e o financiamento (de até $80 \%$ dos itens) era para valores acima de $\mathrm{R} \$ 20$ milhões, com incidência de taxa de juros (BNDES, 2016). Porém, após reformulação do site e das linhas de financiamento, início de 2017 (BNDES, 2017), o BNDES Finem - Meio Ambiente passa a ser chamado de "BNDES Finem - Recuperação e Conservação de Ecossistemas e Biodiversidade" e não abrange mais o escopo deste artigo, que são as OCMRR.

O programa "BNDES Finem - Desenvolvimento integrado dos municípios" é voltado para os projetos multissetoriais, sustentáveis e integrados que estejam alinhados ao planejamento municipal. As OCMRR podem requerer este crédito, desde que comprovem atuação conjunta com as políticas públicas do município. Há a incidência de custo financeiro e taxas de juros e o mesmo contempla projetos a partir de $\mathrm{R} \$ 20$ milhões, sendo que $20 \%$ do valor requerido devem ser dados como pagamento inicial pelo empreendimento.

De forma específica, o BNDES Proplástico oferecia recursos ao desenvolvimento de toda cadeia produtiva do plástico, porém o prazo vigente deste encerrou-se em 2012, na primeira fase, e em 2017, na segunda fase. O valor mínimo das operações era de $R \$ 3$ milhões, na primeira fase, e de $R \$ 5$ milhões, na segunda fase, com incidência de custos e taxa de juros. Não foi identificado informações se o BNDES financiava ou não $100 \%$ dos itens relacionados.

Algo a se destacar é que todas as linhas BNDES Finem e a linha PACEA (Quadro 5 e 6) são créditos com teto superior a $R \$ 20$ milhões, cujos recursos são reembolsáveis, ou seja, com incidência de taxa de juros e outros encargos, o que pode ser inviável para uma OCMRR. Outra observação é que todas as linhas BNDES Finem não possuem participação da credora em $100 \%$ dos itens, exigindo um capital inicial, ou seja, as Organizações devem ter reserva financeira inicial para requerer tais benefícios, o que pode ser considerado um obstáculo a estas, já que dificilmente contam com tais recursos. Vale ressaltar que não foram encontradas informações sobre esta última ressalva para as linhas PACEA e BNDES Proplástico. As outras linhas de crédito têm $100 \%$ da proposta subsidiada pelo BNDES.

Além dessas linhas de crédito, o BNDES oferece recursos através de Fundos (Quadro 7). Os recursos do Fundo Social do BNDES provêm de parte dos lucros anuais do BNDES. Estes recursos são intermediados por agentes financeiros responsáveis pelos repasses em todos os estados, os quais também se ocupam pelo recebimento do pedido, análise e gerenciamento desta transação. $O$ apoio pode ocorrer nas seguintes modalidades: Seleção Pública (editais para apoio direto a projetos produtivos); Premiação (como o Prêmio BNDES de Boas Práticas em Economia Solidária - já encerrado); e Apoio Continuado (com foco na inclusão socioprodutiva, tem duração permanente e é realizado por instituições que intermediam esse apoio). Foi constatado que em 2017 não houve nenhum edital nas seções 'Seleção Pública' e 'Apoio Continuado' que contemple as OCMRR. E, ainda, com relação ao 'Prêmio Boas Práticas em Economia Solidária', a participação dos empreendimentos, neste projeto, depende de o BNDES reconhecer as boas práticas dessas organizações. Para a obtenção dos recursos, exige-se que 0 empreendimento atue na área social. Eventualmente, o BNDES cria linhas de apoio para um público alvo específico, utilizando os recursos do Fundo Social. Um exemplo é a linha "BNDES Fundo Social: Apoio a Projetos de Catadores de Materiais Recicláveis" que visa a inclusão social dos catadores. Esta linha teve início em 2006, porém encerrou-se em 2008.

O Fundo Clima, para a área de Resíduos Sólidos, apoia "[...] os projetos de limpeza urbana e disposição adequada de resíduos sólidos". Contudo, o BNDES não está aceitando novos pedidos, pois afirma não haver recursos. O Fundo de Estruturação de Projetos do BNDES promove projetos de "estudos técnicos ou pesquisas relacionadas ao desenvolvimento econômico e social", além de "orientar a formulação de políticas públicas" (BNDES, 2016), o qual abriu, em 2010, uma chamada pública para a temática dos resíduos sólidos.

Quadro 7 - Fundos oferecidos pelo BNDES

\begin{tabular}{|c|c|c|c|}
\hline FUNDO & $\begin{array}{c}\text { FORMA DE } \\
\text { APOIO }\end{array}$ & PÚBLICO-ALVO & VIGÉNCIA \\
\hline BNDES Fundo Social & Direta & $\begin{array}{c}\text { "Entidades e órgãos públicos; e instituições } \\
\text { privadas, tais como empresas e fundações, } \\
\text { sediadas no país, com ou sem fins } \\
\text { lucrativos." }\end{array}$ & Em vigor \\
\hline
\end{tabular}




\begin{tabular}{|c|c|c|c|}
\hline $\begin{array}{l}\text { BNDES Fundo Social: } \\
\text { Apoio a Projetos de } \\
\text { Catadores de } \\
\text { Materiais Recicláveis }\end{array}$ & Direta & $\begin{array}{l}\text { OCMRR que se enquadrem nos critérios de } \\
\text { elegibilidade e enquadramento jurídico, que } \\
\text { serão analisadas pelos técnicos do BNDES e } \\
\text { com projetos de acordo com o modelo } \\
\text { disponibilizado pelo BNDES. }\end{array}$ & $\begin{array}{l}\text { Expirada (de } \\
2006 \text { a 2008) }\end{array}$ \\
\hline $\begin{array}{l}\text { Fundo Clima - } \\
\text { Resíduos Sólidos }\end{array}$ & $\begin{array}{l}\text { Direta ou } \\
\text { Indireta }\end{array}$ & $\begin{array}{l}\text { Estados, Municípios e Distrito Federal; } \\
\text { entidades da Administração Pública Indireta } \\
\text { Estadual e Municipal, inclusive consórcios } \\
\text { públicos; empresas com sede e } \\
\text { administração no país; e empresários } \\
\text { individuais inscritos no Cadastro Nacional de } \\
\text { Pessoas Jurídicas (CNPJ) e no Registro } \\
\text { Público de Empresas Mercantis. }\end{array}$ & Expirada \\
\hline $\begin{array}{l}\text { Fundo de Estruturação } \\
\text { de Projetos (BNDES } \\
\text { FEP) }\end{array}$ & Direta (editais) & $\begin{array}{l}\text { Pesquisas científicas, projetos; prospecções } \\
\text { e pró-estruturação de projetos. }\end{array}$ & Em vigor \\
\hline
\end{tabular}

Fonte - Elaborado a partir de BNDES (2017, n.p.).

Não houve nenhum Fundo de Investimento, em 2017, com chamada pública aberta para a temática dos resíduos sólidos ou para associações/cooperativas de baixa renda.

Além disso, o BNDES apresenta outras linhas de crédito, como: BNDES Automático; BNDES Finame; BNDES Finame Leasing; Cartão BNDES; BNDES Empréstimo-Ponte; e BNDES Project Finance. Estas linhas podem ser usadas pelas OCMRR, contudo não são especificas a elas. Estas Organizações, na sua maioria, não apresentam as condições econômicofinanceiras (capacidade de pagamento, faturamento, dentre outras) exigidas para a utilização destes instrumentos, tais como: capital próprio, já que há linhas em que não há o financiamento de $100 \%$ dos itens; a parte financiada pelo BNDES tem o custo definido pela Taxa de Juros de Longo Prazo (TJLP) que é a mais baixa das taxas de juros efetivas (de 7 a $7,5 \%$ ao ano, entre 2016 e 2017), segundo BACEN (2017), mas ainda pode ser onerosa para as organizações; os prazos, por serem definidos pelas instituições financeiras credenciadas, podem estar em desacordo com as necessidades das OCMRR; e as garantias exigidas.

O próprio BNDES possui um Fundo Garantidor (BNDES FGI) que é um facilitador de acesso ao crédito, pois divide a responsabilidade com o contratante, mas oferece este serviço com determinado 'custo garantia', o que pode onerar ainda mais os contratos de empréstimo ou financiamento (BNDES, 2016).

Um aspecto a ser considerado é que, apesar de existir a forma de apoio direto e indireto na maioria dos projetos e programas (Quadros 5, 6 e 7), em todos há o requerimento de elaboração de um projeto que passa por uma avaliação da instituição ofertante, seja de apoio direto ou indireto. Exceto o apoio Social "BNDES Microcrédito - Empreendedor" que não apresenta esta informação (sobre a necessidade ou não de projeto elaborado) no site do BNDES. Ocorre que este apoio Social é viabilizado indiretamente, logo, cabe ao intermediador definir as regras de acesso ao crédito. Para o estado de São Paulo, apenas o Banco do Povo Crédito Solidário de Santo André está habilitado para essa transação, porém não foi identificado no site do Banco do Povo de Santo André essa informação. A exigência de projeto formalizado, dentro de normas pré-definidas, pode inviabilizar a tomada desses créditos pelas OCMRR, devido à baixa escolaridade de seus integrantes para interpretar e transcrever os requisitos propostos. Além disso, aqueles com apoio indireto exigem a intermediação de uma instituição financeira que pode não ter interesse na transação. Infere-se, após estas observações, o caráter de exclusão financeira para essas linhas.

Em pesquisa no site do BNDES (2017), observou-se que 12 OCMRR conseguiram recursos do Banco em 16 demandas. Estas ocorreram entre os anos de 2007 e 2012, para diferentes operações: na forma de apoio indireta e reembolsável através do BNDES Finame (3 demandas); como forma de apoio direta e não reembolsável para 'ampliação e aprimoramento da estrutura produtiva postulante' (1 demanda), 'melhora da produtividade e eficiência da cooperativa visando seu fortalecimento' (4 solicitações), 'melhora da produtividade e eficácia da cooperativa visando seu fortalecimento' (2 solicitações), 'aumento da capacidade produtiva, mediante a aquisição de veículos, máquinas e equipamentos e a capacitação de recursos 
humanos' (4 demandas) e 'realização de obras civis, aquisição de veículos, máquinas e equipamentos de infraestrutura física, móveis, utensílios e equipamentos de informática e capacitação de recursos humanos para aumentar a capacidade produtiva da cooperativa' (2 demandas). Esses dados refletem a escassez de recursos destinados às OCMRR no estado, visto existir uma demanda potencial para o atendimento de 236 associações/cooperativas em operação no estado.

É importante mencionar, ainda, que outros estados do sudeste do país apresentam bancos estaduais de desenvolvimento como o Banco de Desenvolvimento de Minas Gerais (BDMG) e o Banco de Desenvolvimento do Espírito Santo (BANDES), ao contrário do estado de São Paulo, que depende da atuação do BNDES, que por sua vez, não representa efetivamente um órgão financiador de OCMRR.

\section{INSTITUIÇÕES FINANCEIRAS NÃO-BANCÁRIAS: AGÊNCIAS DE DESENVOLVIMENTO, FOMENTO E PESQUISA ESTADUAIS E NACIONAIS}

A Fundação de Amparo à Pesquisa do Estado de São Paulo (FAPESP) é uma agência de fomento de âmbito estadual que, além de financiar projetos de pesquisas de acadêmicos solicitantes, realiza chamadas de propostas anualmente dentro de temáticas selecionadas. A instituição divulga, em seu endereço eletrônico, suas chamadas desde 2006, no entanto, não foram identificadas propostas que favoreciam as OCMRR (FAPESP, 2017).

A Agência de Desenvolvimento Paulista - DESENVOLVE SP possui linhas de crédito (Quadro 8), além de ser credenciada junto ao BNDES e outros, como instituição financeira de apoio conjunto aos requisitantes de recursos (DESENVOLVE SP, 2016). Estas linhas, porém, são destinadas principalmente às micro e pequenas empresas que apresentem capacidade de pagamento. A Desenvolve SP não possui agências, sendo que a principal forma de acesso às linhas de financiamento é pela internet ou entrando em contato com alguma das entidades filiadas (70 entidades/associações empresariais). Para requerer um recurso da Desenvolve SP é necessário apresentar um Projeto de Investimento ou de Inovação, elaborado conforme tutorial apresentado no site. Este oferece consultoria paga para auxílio nas resoluções de cadastro até à confecção dos projetos solicitados. Mesmo apresentando tutorial para várias ações, isso não inclui aqueles que não têm acesso ao computador, o que também, expressa um caráter de exclusão financeira. $\mathrm{O}$ crédito depende de garantias que podem ser obtidas a partir da contratação de um Fundo Garantidor ou Avalista pago (apresentados no próprio site) e isto pode vir a ser um obstáculo às OCMRR.

Quadro 8 - Relação de linhas de crédito da Desenvolve SP.

\begin{tabular}{|c|c|c|c|}
\hline \\
\hline $\begin{array}{l}\text { LINHA EXCLUSIVA DA } \\
\text { DESENVOLVE SP }\end{array}$ & $\begin{array}{c}\text { LINHA EM } \\
\text { PARCERIA COM } \\
\text { A FINEP }\end{array}$ & $\begin{array}{l}\text { LINHA EM PARCERIA } \\
\text { COM O FUNCET }\end{array}$ & $\begin{array}{l}\text { LINHA EM PARCERIA } \\
\text { COM O BNDES }\end{array}$ \\
\hline Linha Economia Verde & \multirow{3}{*}{ Inovacred } & \multirow{5}{*}{$\begin{array}{l}\text { Linha de Incentivo à } \\
\text { Inovação }\end{array}$} & $\begin{array}{l}\text { BNDES MPME } \\
\text { Inovadora }\end{array}$ \\
\hline $\begin{array}{l}\text { Linha Economia Verde- } \\
\text { Máquinas }\end{array}$ & & & BNDES Automático \\
\hline Linha de Incentivo à Tecnologia & & & BNDES Progeren \\
\hline $\begin{array}{l}\text { Financiamento ao Investimento } \\
\text { Paulista (FIP)-Meio Ambiente } \\
\end{array}$ & \multirow{2}{*}{$\begin{array}{l}\text { Inovacred } \\
\text { Expresso }\end{array}$} & & BNDES Finame \\
\hline FIP-Simplificado & & & Não divulgado \\
\hline
\end{tabular}

Fonte - Elaborado a partir de Desenvolve SP (2016, n.p.).

Das agências nacionais, tem-se o Conselho Nacional de Desenvolvimento Científico e Tecnológico (CNPq) que disponibiliza recursos financeiros para diversas pesquisas, dentre elas sobre Resíduos Sólidos. Além disso, esta instituição já elaborou algumas chamadas Públicas envolvendo este tema e as OCMRR (Quadro 9). De 2013 até dezembro de 2017, identificou-se 13 chamadas para apoio financeiro, pelo CNPq, nas quais as OCMRR se enquadrariam. Dessas, três foram diretamente elaboradas para atender OCMRR do movimento de Economia Solidária (nos anos de 2013, 2015 e 2017). Percebe-se que das 13 chamadas, 7 ocorreram em 2013, 2 em 2014, 2 em 2015 e apenas 1 em 2016 e 2017. Vale a ressalva que o presente 
artigo assume, como recorte temporal para a análise dos dados desta instituição, as chamadas públicas a partir de 2013, desconsiderando as anteriores, com data desde 2006 (CNPq, 2017).

Quadro 9 - Relação de chamadas públicas do CNPq abrangendo o estado de SP.

\begin{tabular}{|c|c|}
\hline Chamadas & Inscrições \\
\hline $\begin{array}{c}\text { CNPq/MTb-SENAES № 27/2017 - Incubadoras de } \\
\text { Empreendimentos Econômicos Solidários }\end{array}$ & 06/10/2017 a 06/11/2017 \\
\hline MCTI/CNPQ № 01/2016 - Universal & $12 / 01 / 2016$ a $29 / 02 / 2016$ \\
\hline $\begin{array}{l}\text { MCTI/CNPq/MTE/SENAES № 21/2015 - Incubadoras } \\
\text { Tecnológicas de Empreendimentos Econômicos Solidários }\end{array}$ & 09/10/2015 a 23/11/2015 \\
\hline $\begin{array}{l}\text { CNPq/ MCTI № 25/2015 Ciências Humanas, Sociais e Sociais } \\
\text { Aplicadas }\end{array}$ & $13 / 10 / 2015$ a $11 / 11 / 2015$ \\
\hline $\begin{array}{c}\text { MCTI/CNPQ/MEC/CAPES № 22/2014 - Ciências Humanas, } \\
\text { Sociais e Sociais Aplicadas }\end{array}$ & 06/10/2014 a 05/11/2014 \\
\hline Universal MCTI/CNPQ № 14/2014 & $30 / 04 / 2014$ a $16 / 06 / 2014$ \\
\hline MCTI/SECIS/MTE/SENAES/CNPq Nº 89/2013 & 03/10/2013 a 18/11/2013 \\
\hline $\begin{array}{c}\text { Projetos CNPq / MIT no 88/2013 - Programa de Cooperação } \\
\text { CNPq / Massachusetts Institute of Technology - MIT. }\end{array}$ & 02/09/2013 a 16/10/2013 \\
\hline MCTI-CNPq/MDS-SAGI № 24/2013 - Desenvolvimento Social & 02/09/2013 a 16/10/2013 \\
\hline $\begin{array}{l}\mathrm{MCTI} / \mathrm{CNPq} / \mathrm{CT} \text {-Hidro } \mathrm{N} \text { o } 36 / 2013 \text { - Conservação da água e } \\
\text { manejo, recuperação e conservação do solo e da } \\
\text { biodiversidade }\end{array}$ & 09/08/2013 a 23/09/2013 \\
\hline $\mathrm{MCTI} / \mathrm{CNPq} / \mathrm{CT}-$ Biotec № 30/2013 & $22 / 07 / 2013$ a $10 / 09 / 2013$ \\
\hline Universal - MCTI/CNPq № 14/2013 & 09/04/2013 a 23/05/2013 \\
\hline $\begin{array}{l}\text { CNPq/FWO N 52/2012 Programa de Cooperação entre o } \\
\text { CNPq e a Fundação de Pesquisa Flandres (FWO) da Bélgica }\end{array}$ & 06/12/2012 a 24/01/2013 \\
\hline
\end{tabular}

Fonte - Elaborado a partir de CNPq (2017, n.p.).

A Financiadora de Estudos e Projetos (FINEP) disponibiliza apoio e financiamento "não reembolsável", por chamadas públicas, destinado a empresas e instituições governamentais. Foram identificadas apenas as chamadas 07/2009 e 06/2010, para a temática "Saneamento Ambiental e Habitação", as quais não abrangeram as OCMRR do estado de SP. (FINEP, 2016)

De acordo com a análise das agências de desenvolvimento, fomento e pesquisa, pode-se inferir o quão dependentes são as OCMRR das instituições de ensino (caso do CNPq) e/ou de órgãos/grupos externos (como ocorre com a FAPESP, Desenvolve SP e Finep). Para requerer recursos financeiros, as OCMRR necessitam que instituições de ensino e/ou órgãos/grupos externos sejam os intermediadores e proponentes dos projetos e, em alguns casos, inclusive dos recursos, o que reflete que esta 'dependência' seja uma condição ou até mesmo uma norma para acesso aos recursos.

\section{INSTITUIÇÕES FINANCEIRAS NÃO-BANCÁRIAS: INSTITUIÇÕES PÚBLICAS}

O governo federal tem elaborado algumas medidas para o fortalecimento das OCMRR, na tentativa de promoção da inclusão social dos catadores, principalmente através de seus Ministérios (Meio Ambiente, Trabalho e Previdência Social, e Cidades).

O Ministério do Meio Ambiente (MMA) apresenta o Fundo Nacional do Meio Ambiente (FNMA). Este Fundo surgiu em 1989, com a Lei 7.797, com o intuito de "[...] contribuir, como agente financiador, por meio da participação social, para a implementação da Política Nacional do Meio Ambiente" (MMA, 2016, n.p.). Desde seu início até o momento, o Fundo já apoiou 1.439 projetos em várias áreas, inclusive para a constituição de OCMRR. Em 2006, três projetos foram aprovados nos municípios de Amparo, Cerquilho e Salto, tendo como principal foco o "[...] fomento a projetos de gestão integrado de resíduos sólidos" (FNMA, 2007, n.p.). Em 2009, dois projetos foram destinados ao "Fomento a Projetos de Gerenciamento e Disposição de Resíduos em Municípios de Médio Porte" (FNMA, 2010, n.p.). Percebe-se, de maneira geral, que este Fundo visa estimular a elaboração dos Planos Municipais de Gestão Integrada de Resíduos Sólidos (PMGIRS), oferecendo recursos apenas a municípios que tenham elaborado seus Planos. Vale ressaltar que a elaboração deste só é obrigatória para aqueles municípios com mais de 20 mil habitantes (PUPIN e BORGES, 2015; PUPIN; BRUMATTI; BORGES, 2015). 
O Ministério do Trabalho e Previdência Social (MTPS) tem como objetivo, dentre outras funções, desenvolver ações de apoio, fomento e atividades de capacitação, qualificação e assistência técnica no que se refere aos Planos Plurianuais do Governo Federal (MTPS, 2017, n.p.). Neste sentido, a temática dos Resíduos Sólidos aparece como um Programa de apoio do MTPS vinculado à Secretaria Nacional de Economia Solidária (SENAES), no Plano Plurianual (PPA) de 2012 - 2015. Este Programa não é uma linha de crédito e sim de apoio, fomento e assessoria para que as Organizações possam ter acesso aos recursos. Em 2015, houve uma chamada pública para a disponibilização de recursos não reembolsáveis no valor de até $R \$$ $30.000,00$ para solicitar. A "Avaliação de Mérito", que ocorre via projeto e documentação enviada, é feita por requisitos expostos no portal do Programa (SENAES, 2017). Os anexos solicitados pelo Programa impõem um obstáculo aos requerentes por ser burocrático. No entanto, isto se justifica por se tratar de recursos públicos, mas pode inviabilizar o acesso. Fora esse Programa, o portal da SENAES informa mais outros quatro programas voltados para empreendimentos solidários, que poderiam abranger as OCMRR. Para o PPA 2016 - 2019, não há nenhum edital ou chamada pública divulgado.

O MTPS apresenta, ainda, o Programa de Geração de Emprego e Renda (PROGER), que institui linhas de crédito destinadas a diversos setores da economia, através da utilização do Fundo de Amparo ao Trabalhador (FAT). Dentre essas linhas, destaca-se o PROGER Urbano Investimento - Cooperfat, a qual financia 'investimento' e 'capital de giro' para OCMRR e seus membros. As instituições financeiras intermediárias são: Banco do Brasil; Banco do Nordeste; Caixa Econômica Federal; Banco da Amazônia; FINEP; e BNDES (operações diretas e indiretas) (MTPS, 2017). Dentre as instituições autorizadas a promover esta linha de crédito, a única que apresenta claramente a linha COOPERFAT é o Banco do Nordeste. Porém, este e o Banco da Amazônia não atuam no estado de São Paulo, não sendo analisados neste trabalho.

O Ministério das Cidades (MCidades), em conjunto com sua Secretaria Nacional de Saneamento Ambiental (SNSA), disponibiliza recursos financeiros através do: programa de Saneamento Básico que envolve todo o manejo de Resíduos Sólidos (desenvolvido com a Caixa Econômica Federal - Quadro 2); financiamento público nas diretrizes do projeto Trabalho Socioambiental, o qual não é efetivamente voltado às organizações produtivas e sim para assistência e inclusão social dos catadores; financiamento privado que segue diretrizes do Trabalho Socioambiental e também do Trabalho Social; e Debêntures em Infraestrutura de Saneamento, o único voltado à estrutura física das Organizações. Estes programas e financiamentos são ligados ao requerimento e planejamento dos projetos do Poder Público Municipal (MCIDADES, 2016).

A Fundação Nacional de Saúde (FUNASA) possui um Programa de Resíduos Sólidos, que tem como objetivo "[...] contribuir para a melhoria das condições de saúde da população, com a implantação de projetos de coleta, transporte, destinação e disposição final adequada de resíduos sólidos". Este programa oferece recursos para "[...] as ações de Gerenciamento de Resíduos Sólidos de responsabilidade e titularidade pública" (FUNASA, 2017, n.p.), após a elaboração do Plano Municipal de Gestão Integrada de Resíduos Sólidos (PMGIRS). Durante os quatro anos de vigência do Plano Plurianual 2012-2015 (FUNASA, 2016), a Funasa atendeu 410 cooperativas para a ação de fomento e fortalecimento de associações/cooperativas e redes de cooperação de catadores para atuação na coleta seletiva e nas cadeias da reciclagem, das quais 12 propostas foram para o estado de São Paulo, nos anos de 2012 a 2014. Em 2015 não houve solicitação de proposta pelo estado, porém o site do Programa já cita ações para o PPA 2016-2019, sem especificar o atendimento às associações/cooperativas (FUNASA, 2017).

O Banco do Povo Paulista é o "programa de microcrédito" para a produção do estado de SP para "[...] empreendedores formais e informais, associações e cooperativas produtivas ou de trabalho, que demonstrem faturamento bruto inferior a $\mathrm{R} \$ 360$ mil nos últimos 12 meses." (BPP, 2017a, n.p.). O banco atua em 494 municípios (BPP, 2017b), dos 645 totais do estado. Esta instituição apresenta linhas de crédito para investimento fixo, capital de giro e consertos de equipamentos, máquinas e ferramentas. Não foram encontrados dados sobre a captação de recursos, especificamente, por OCMRR. Vale ressaltar que o acesso é mais facilitado e com juros reduzidos (pré-fixado em apenas $0,35 \%$ ao mês), no entanto, o valor máximo liberado é de $R \$ 25.000,00$ para associações/cooperativas (BPP, 2017a). 
O Fundo Estadual Científico e Tecnológico (Funcet) objetiva "[...] estimular a inovação, o desenvolvimento tecnológico e o incremento da competitividade das empresas e da economia do Estado [de SP], por meio de financiamentos em condições especiais". (FUNCET, 2016). Para requerer o crédito é necessário que ocorra a abertura de edital, e o último é de 2010. Além disso, este fundo tem parceria com o Programa Desenvolve SP, fornecendo certos benefícios, como o auxílio no pagamento dos juros das transações em linhas que incentivam a inovação (como apresentado no Quadro 8).

Nesta seção, assinalamos que a maioria dos projetos depende de parceria com as Prefeituras Municipais, o que pode vir a ser um complicador para as OCMRR, uma vez que as primeiras, de maneira geral, não apresentam um compromisso com a temática, visto a pouca quantidade de municípios que autodeclaram seus dados sobre o manejo de resíduos sólidos no Sistema Nacional de Informações Sobre Saneamento (SNIS) de maneira clara, contínua e confiável (PUPIN e BORGES, 2015; PUPIN; BRUMATTI; BORGES, 2015). É importante considerar que o SNIS é tido como uma base de dados do Governo Federal para conhecimento do tema, pelos responsáveis e pela sociedade, e que deve servir de ponto de apoio para ações e investimentos do Governo na área. Portanto, esse comportamento do Poder Público Municipal fere as necessidades da população.

\section{CONSIDERAÇÕES FINAIS}

Para a elaboração deste artigo reconheceu-se os inúmeros desafios que permeiam a constituição (e possível continuidade) de uma Organização de Catadores de Material Reciclável e Reutilizável (OCMRR). Situações estas que partem desde as limitações do ser catador, passando pela extensa burocracia da formalização do empreendimento e recaindo nas dificuldades de gestão. Salientou-se também sobre a necessidade de capital, tanto para a aquisição de galpões e equipamentos em geral, quanto para sanar possíveis obrigações.

Neste ínterim, de acordo com autores e pesquisas consultados para a elaboração deste artigo, depreende-se que há dificuldades por partes das OCMRR para a obtenção de crédito (através de empréstimos e financiamentos), o que, inclusive, está relacionado à exclusão financeira dessas organizações. Após a abordagem desse cenário, estabeleceu-se como objetivo identificar e analisar se os créditos ofertados pelas instituições financeiras, do estado de São Paulo, e as suas condições/ exigências são adequadas à realidade das OCMRR. Para tal, foram utilizadas as definições do Banco Central do Brasil para identificar quais instituições seriam analisadas no estado de São Paulo.

Sobre as inquirições iniciais desta análise a respeito do Sistema Financeiro, pôde-se inferir que o mesmo não possui maiores interesses em atender a demanda de crédito (empréstimos e financiamentos) provenientes das OCMRR, já que a oferta de crédito se mostra insuficiente e inadequada ao acesso destas Organizações. Isto se deve, em parte, aos tipos de crédito disponibilizados pelas instituições financeiras bancárias. De acordo com a análise, as instituições Itaú Unibanco, Santander e Bradesco oferecem linhas tradicionais para pequenas e médias empresas que abrangem o público em geral, não havendo linhas que supram as dificuldades de acesso e utilização das OCMRR, já que, para estas linhas, há incidência de taxa de juros, taxas administrativas, custos outros, além de prazo de pagamento reduzido.

Já as instituições financeiras de natureza especial (Caixa Econômica, Banco do Brasil e BNDES) oferecem (ou ofereceram) recursos a estas Organizações por meio de crédito (empréstimo ou financiamento), porém a análise aponta que, mesmo as linhas mais direcionadas, possuem complicadores que podem ser considerados intransponíveis para essas Organizações. Além disso, a maioria das linhas de crédito destas instituições exige um pagamento inicial elevado, o que não configura, em geral, a realidade do caixa de uma OCMRR.

Identificam-se outros meios de captação de recursos disponíveis no mercado, através de apoio financeiro. Estes apoios levam em consideração a vulnerabilidade destes empreendimentos ao acesso formal de crédito, e atuam por meio de premiações e/ou programas de apoio financeiro. Para estas formas de crédito, identificam-se as instituições Itaú Unibanco, Santander, Caixa Econômica, Banco do Brasil, BNDES, CNPq, FINEP, MMA, MTPS, MCidades, FUNASA, Banco do Povo Paulista e a Funcet. 
Nestes casos, é requerido o acompanhamento de editais e acesso por internet, o que, no geral, pode ser considerado um limitador de participação para a maioria das OCMRR. Esse fato poderia significar uma oportunidade, visto a facilidade de acesso, porém esta possibilidade só é legítima para aqueles que possuem computador, acesso à rede de internet e capacitação para tal, condições não existentes para a maior parte das OCMRR. Além disso, muitos desses programas e fundos são esporádicos e limitam o número de beneficiários, visto que acontecem por meio de editais, campanhas ou até por sobras de Fundos de Investimento. Assim, observase um hiato entre o momento de demanda (necessidade) e o de disponibilização do recurso, inviabilizando o suprimento de necessidades correntes.

Identifica-se, ainda, que em muitos casos há a exigência de projetos e outras formalidades que devem ser atendidos pela demandante do recurso, ou seja, pelas próprias OCMRR ou em conjunto com Prefeituras Municipais ou Instituições de Ensino. A necessidade de agentes externos para viabilizar a captação de recurso é um indicativo de subordinação/dependência dessas Organizações. Fora estes aspectos, verificou-se que alguns desses programas não ofertam crédito, especificamente, mas sim assessoria e apoio à gestão das OCMRR. Nas instituições Bradesco, Fapesp e Agência de Desenvolvimento Paulista não foram encontradas formas de beneficiamento direto para essas Organizações.

Ressalva-se, após as análises apresentadas neste artigo, a necessidade de novos estudos, feitos de forma pontual e direta com as OCMRR que captaram ou receberam recursos de instituições bancárias (empréstimo ou financiamento) ou por programas de entidades governamentais (via programas específicos, editais ou ainda, especificamente, pelo BNDES) com a finalidade de identificar as reais dificuldades nesse processo de captação. Além disso, destaca-se a importância de uma análise a nível nacional, a fim de identificar e analisar as condições de oferta de crédito dos bancos de desenvolvimento estaduais para as OCMRR. Estes estudos poderiam contribuir para a construção de um panorama mais amplo sobre o tema da captação de recursos por associações ou cooperativas de materiais reutilizáveis e recicláveis. Acrescenta-se ainda que o artigo aponta a necessidade de estudos e abordagens que resultem em dados numéricos a respeito da exclusão financeira de empreendimentos sociais.

\section{REFERÊNCIAS}

ABCR. Associação Brasileira de Captadores de Recursos. 2017. Disponível em: $<$ http://captadores.org.br/>. Acesso em: 27 mar. 2017.

ABRELPE. Associação Brasileira de Empresas de Limpeza Pública e Resíduos Especiais. Quem somos. 2016. Disponível em: <http://www.abrelpe.org.br/abrelpe quemsomos.cfm>. Acesso em: 28 abr. 2016.

BB. Banco do Brasil. Produtos e servicos. 2017. Disponível em: <http://www.bb.com.br/pbb/pagina-inicial/voce/produtos-e-servicos\#/>. Acesso em: 06 mar. 2017.

BCB. Banco Central do Brasil. 50 maiores bancos e o consolidado do Sistema Financeiro Nacional. 2016. Disponível em: <http://www4.bcb.gov.br/top50/port/top50.asp >. Acesso em: 03 abr. 2017.

BCB. Indicadores de Conjuntura. 2017. Disponível em: $<$ http://www.bcb.gov.br/pec/Indeco/Port/ indeco.asp >. Acesso em: 03 abr. 2017.

BCB. Perfil cidadão. Perguntas frequentes e cartilhas. Perguntas frequentes. Empréstimos e financiamentos. 2018a. Disponível em: <http://www.bcb.gov.br/pre/bc atende/port/servicos9.asp $>$. Acesso em: 30 jan. 2018.

BCB. Sistema Financeiro Nacional. Informações cadastrais e sobre Contabilidade. Informações cadastrais. Relação de Agências, Postos e Filiais de Administradoras de Consórcio (transferência de arquivos). 2018b. Disponível em: $<$ https://www.bcb.gov.br/fis/info/agencias.asp >. Acesso em 01 fev. 2018. 
BNDES. Banco Nacional de Desenvolvimento Econômico e Social. Áreas de atuação. 2016. Disponível em: <http://www.bndes.gov.br/SiteBNDES/bndes/bndes pt/Areas de Atuacao/>. Acesso em: 18 abr. 2016.

BNDES. Banco Nacional de Desenvolvimento Econômico e Social. Áreas de atuação. 2017. Disponível em: <http://www.bndes.gov.br/SiteBNDES/bndes/bndes pt/Areas de Atuacao/>. Acesso em: 27 mar. 2017.

BPCS. Banco do Povo - Crédito Solidário de Santo André. Quem somos. Disponível em: $<$ http://www.bpcs.org.br/quem-somos/>. Acesso em 03 abr. 2017.

BPP. Banco do Povo Paulista. Sobre o Banco. 2017a. Disponível em:

$<$ http://www.bancodopovo.sp.gov.br/?page id=7>. Acesso em: 30 mar. 2017.

BPP. Home. 2017b. Disponível em: <http://www.bancodopovo.sp.gov.br/>. Acesso em: 07 mar. 2017.

BRADESCO. Banco Bradesco. Produtos e serviços. 2017. Disponível em: $<$ https://banco.bradesco/html/classic/produtos-servicos/index.shtm>. Acesso em: 27 mar. 2017.

BRASIL. Lei $\mathbf{n}^{\circ}$ 5.764, de 16 de Dezembro de 1971. Disponível em: <http://www.planalto.gov.br/CCivil 03/leis/L5764.htm>. Acesso em: 01 fev. 2018.

BRASIL. Lei no 10.406, de 10 de janeiro de 2002. Disponível em: < http://www.planalto.gov.br/ccivil 03/Leis/2002/L10406.htm>. Acesso em:13 mar. de 2017.

CEF. Caixa Econômica Federal. Resíduos Sólidos Urbanos. 2017. Disponível em: $<$ http://www1.caixa.gov.br/gov/gov social/municipal/assistencia tecnica/produtos/repasses/resi duos solidos urbanos/saiba mais.asp>. Acesso em: 28 mar. 2017.

CNPq. Conselho Nacional de Desenvolvimento Científico e Tecnológico. Chamadas-públicas. 2017. Disponível em: <http://cnpq.br/chamadas-publicas>. Acesso em: 23 dez. 2017.

COSTA, W. B.; CHAVES, M. R. Informalidade e precarização do trabalho de catação de materiais recicláveis no Brasil: pontos para debate. In: Anais da XIII Jornada do Trabalho. Presidente Prudente: outubro, 2012.

CROCCO, M. A.; SANTOS, F.; FIGUEIREDO, A. Exclusão financeira no Brasil: uma análise regional exploratória. Revista de Economia Política, vol. 33, no 3 (132), pp. 505-526, julhosetembro/2013. https://doi.org/10.1590/S0101-31572013000300008

DESENVOLVE SP. Agência de Desenvolvimento Paulista. Opções de crédito. 2016. Disponível em: <http://www.desenvolvesp.com.br/empresas/opcoes-credito>. Acesso em: 07 dez. 2016.

FAPESP. Fundação de Amparo à Pesquisa do Estado de São Paulo. 2017. Disponível em: $<$ http://www.fapesp.br/>. Acesso em: 07 dez. 2017.

FAT. Fundo de Amparo ao Trabalhador. Página Inicial. Programas e ações. Programa Nacional do Microcrédito Produtivo Orientado. 2016. Disponível em: <http://portalfat.mte.gov.br/programas-eacoes-2/programa-nacional-do-microcredito-produtivo-orientado-pnmpo/>. Acesso em: $07 \mathrm{dez}$. 2017

FBB. Fundação Banco do Brasil. O Programa. 2016. Disponível em: $<$ http://www.fbb.org.br/main.jsp?lumPageld=8AE389DB47275C6301473C0CB3141333\&lumlte mld=8AE389DB47275C6301473C15C41F2878>. Acesso em: 25 abr. 2016.

FINEP. Financiadora de Estudos e Projetos. Apoio e financiamento. 2016. Disponível em: $<$ http://www.finep.gov.br/apoio-e-financiamento-externa/o-que-apoiamos >. Acesso em: 27 abr. 2016.

FNMA. Fundo Nacional do Meio Ambiente. Ministério do Meio Ambiente. Relatório de Gestão: Exercício de 2006. 2007. Disponível em: <http://www.mma.gov.br/apoio-a-projetos/fundonacional-do-meio-ambiente/relatorios-de-gestao-e-auditoria\#ano2006 >. Acesso em: 06 dez. 2016.

FNMA. Relatório de Gestão: Exercício de 2009. 2010. Disponível em: $<$ http://www.mma.gov.br/estruturas/fnma/ arquivos/relatoriogestaofnma 2009 1.pdf $>$. Acesso em: 06 dez. 2016. https://doi.org/10.1590/S1413-73722010000100002 
FUNASA. Fundação Nacional de Saúde. Programa de Resíduos Sólidos Urbanos. 2016. Disponível em: <http://www.funasa.gov.br/site/programa-de-residuos-solidos-urbanos/>. Acesso em: 28 mar. 2017.

FUNASA. Fundação Nacional de Saúde. Resíduos Sólidos. 2017. Disponível em: $<$ http://www.funasa.gov.br/site/engenharia-de-saude-publica-2/residuos-solidos/>. Acesso em: 28 mar. 2017.

FUNCET. Fundo Estadual Científico e Tecnológico. 2016. Disponível em: $<$ http://www.desenvolvimento.sp.gov.br/fundo-estadual-cientifico-e-tecnologico-(funcet)>. Acesso em: 27 abr. 2016.

FURLANI, J. R. A. Como funciona o sistema financeiro nacional. Banco Central do Brasil Programa de educação financeira. BC e a Universidade. 2007. Disponível em: $<$ http://www.bcb.gov.br/Pre/bcUniversidade/Palestras/BC\%20e\%20Universidade\%2013.4.2007. ppd>. Acesso em: 01 fev. 2017.

GAIGER, L. I. Significados e tendências da economia solidária. In Sindicalismo e Economia Solidária. Reflexões sobre o projeto da CUT. 1999. Disponível em: http://cessangicos. blogspot.com.br/2011/06/significados-e-tendencias-da-economia.html. Acesso em: 28 mar. 2017.

GONÇALVES, M. A. Relatório Final de Pesquisa. CNPq - Conselho Nacional de Desenvolvimento Científico. 2007.

GRIMBERG, E. Coleta seletiva com inclusão social: Fórum Lixo e Cidadania na Cidade de São Paulo. Experiência e desafios. São Paulo: Instituto Pólis, 2007. 148p. (Publicações Pólis, 49)

IBGE. Instituto Brasileiro de Geografia e Estatística. Informações sobre os municípios brasileiros. 2016. Disponível em: <http://www.cidades.ibge.gov.br/xtras/home.php>. Acesso em: 20 abr. 2016.

ITAÚ. Banco Itaú. Produtos para empresas. Créditos e financiamentos. 2017a. Disponível em: <https://www.itau.com.br/empresas/creditos-financiamentos/>. Acesso em: 28 mar. 2017.

ITAÚ. Sustentabilidade. Riscos e oportunidades socioambientais. Ecomudança. 2017b. Disponível em: <https://www.tau.com.br/sustentabilidade/riscos-e-oportunidades-socioambientais/ecomudanca/>. Acesso em: 03 abr. 2017.

LANA, T. P. Exclusão financeira e sua relação com a pobreza e desigualdade de renda no Brasil. 2013. 238 f. Tese (Doutorado em Economia) - Centro de Desenvolvimento e Planejamento Regional, Universidade Federal de Minas Gerais, Belo Horizonte.

MCidades. 2016. Disponível em: <https://www.cidades.gov.br/>. Acesso em: 05 dez. 2016.

MCidades. Cidades Sustentáveis. Resíduos Sólidos. Catadores de materiais recicláveis. 2017. Disponível em: <http://www.mma.gov.br/cidades-sustentaveis/residuossolidos/catadores-de-materiais-reciclaveis >. Acesso em 03 abr. 2017.

MCidades. Ministério das Cidades. Sistemática 2012: Manual para apresentação de propostas para sistemas públicos de manejo de resíduos sólidos urbanos. Secretaria Nacional de Saneamento Ambiental. 2012.

MMA. Ministério do Meio Ambiente. Fundo Nacional do Meio Ambiente. 2016. Disponível em: $<$ http://www.mma.gov.br/fundo-nacional-do-meio-ambiente>. Acesso em: 05 dez. 2016.

MTPS. Ministério do Trabalho e Previdência Social. Programas e ações. 2017. Disponível em: $<$ http://portalfat.mte.gov.br/programas-e-acoes-2/programas-de-geracao-de-emprego-e-rendaproger/linhas-de-credito/>. Acesso em: 07 mar. 2017.

MUÑOZ. E. F. P. Associativismo e Cooperativismo: uma estratégia de organização empreendedora e solidária. 2012. Instituto Federal de Santa Catarina. (Desenvolvimento de material didático ou instrucional - Cartilha de Formação sobre Cooperativismo).

ONUBR. Organização das Nações Unidas no Brasil. Objetivo 8. 2016. Disponível em: $<$ https://nacoesunidas.org/pos2015/ods8/>. Acesso em: 18 abr. 2016. 
PUPIN, P. L. F; BORGES, A. C. G. A vulnerabilidade dos dados dos Municípios Paulistas sobre Resíduos Sólidos no sistema autodeclaratório do SNIS. Revista VITAS - Visões

Transdisciplinares sobre Ambiente e Sociedade, Ano V, n 9, 2015.

PUPIN, P. L. F; BRUMATTI, L. M.; BORGES, A. C. G. A análise dos dados sobre Resíduos Sólidos nas bases do PNSB e do SNIS. Revista Nacional de Gerenciamento de Cidades, v. 03, n 21, 2015. https://doi.org/10.17271/2318847232120151151

SANTANDER UNIVERSIDADES. Prêmios. 2016. Disponível em:

$<\mathrm{https}: / / \mathrm{ww}$.santanderuniversidades.com.br/revistan.p.remios/index.html\#premio >. Acesso em: 18 abr. 2016.

SANTANDER. Pessoa Jurídica. Empréstimos e financiamentos. 2017. Disponível em: <https://www.santander.com.br/br/pessoa-juridica/negocios-empresas/emprestimos-e-financiamentos>. Acesso em: 29 mar. 2017.

SEBRAE. Minha Empresa Sustentável: Cooperativa de Reciclagem - Cuiabá, MT: Sebrae, 2017. 25p.

SENAES. Economia Solidária. Programas e ações. 2017. Disponível em: $<$ http://acesso.mte.gov.br/ecosolidaria/programa-economia-solidaria-em-desenvolvimento/>. Acesso em: 29 mar. 2017.

SILVA, S. P. A organização coletiva de catadores de material reciclável no brasil: dilemas e potencialidades sob a ótica da economia solidária. Instituto de Pesquisa Econômica Aplicada - IPEA, 2017.

SILVA, S. P.; GOES, F. L.; ALBINO, R. A. Situação social das catadoras e dos catadores de material reciclável e reutilizável - Brasil. Instituto de Pesquisa Econômica Aplicada - IPEA, 2013.

SIMPSON, W.; BUCKLAND, J. Dynamics of the Location of Financial Insitutions: who is serving the inner city?. Economic Development Quaterliy, v. 30, n. 4, p. 358-370, 2016.

https://doi.org/10.1177/0891242416665908

SNIS. Sistema Nacional de Informações sobre Saneamento. Diagnóstico do Manejo de Resíduos Sólidos Urbanos - 2016. Brasília: MCidades/SNSA. 2018. Disponível em:

<http://www.snis.gov.br/diagnostico-residuos-solidos/diagnostico-rs-2016>. Acesso em: 01 fev. 2018.

SOUZA, H. P. B. Desregulamentação financeira, concentração bancária e exclusão financeira no Brasil na década de 1990. In: XI Congresso Brasileiro de História Econômica, 2015, Vitória - ES. Anais XI ABPHE, 2015. p. 1-16.

TURRIONI, J. B.; MELLO, C. H. P. Metodologia de Pesquisa em Engenharia de Produção: estratégias, métodos e técnicas para condução de pesquisas quantitativas e qualitativas. Itajubá: UNIFEI, 2012.

UNISOL Brasil. Central de Cooperativas e Empreendimentos Solidários. Quem somos. 2016. Disponível em: <http://www.unisolbrasil.org.br/quem-somos/>. Acesso em: 29 abr. 2016.

UNITRABALHO. Sobre a Unitrabalho. 2016. Disponível em:

$<$ http://www.unitrabalho.org.br/spip.php?article3>. Acesso em: 29 abr. 2016.

Recebido em: 22/05/2018

Aceito para publicação em: 05/04/2019 